\title{
1 Cyclically resolved flame and flow imaging in an alcohol fuelled SI engine
}

Mohammadmohsen Moslemin Koupaie, Alasdair Cairns. University of Nottingham

Jun Xia, Hassan Vafamehr, Thompson Lanzanova. Brunel University London

\section{Abstract}

The work was concerned with improving understanding of the interaction of the bulk in-cylinder flow with turbulent premixed flame propagation when using varied fuels including iso-octane, ethanol or butanol. The experiments were performed in a single cylinder research engine equipped with a modern central direct injection combustion chamber and Bowditch style optical piston. Results were obtained under typical part-load engine operating conditions. High speed cross-correlated particle image velocimetry was undertaken at $1500 \mathrm{rpm}$ under motoring conditions with the plenum pressure set to 0.5 bar absolute, with the horizontal imaging plane fixed $10 \mathrm{~mm}$ below the combustion chamber "fireface". Comparisons were made to CFD computations of the flow. Complementary flame images were then obtained via natural light (chemiluminescence) over multiple engine cycles. The flame images revealed the tendency of the flame to migrate towards the hotter exhaust side of the combustion chamber, with no complementary bulk air motion apparent in this area in the imaging plane. In terms of fuel effects, the addition of $16 \%$ butanol to iso-octane resulted in marginally faster combustion. Fastest combustion was observed with ethanol, in good agreement with laminar burning velocity correlations within the literature. The ethanol could be seen to offset the tendency of migration of the flame toward the exhaust walls under the fixed spark timing conditions. This exhaust migration phenomenon has been noted previously by others in optical pent-roofed engines but without both flow and flame imaging data being available. The results may imply that the spark plug should ideally be biased further towards the intake side of the chamber if the flame is to approach the intake and exhaust walls at similar times resulting in symmetrical flame propagation, reduced premature wall quenching and hence increase combustion stability and thermal efficiency. Such a layout is typically not preferred due to the priority given to the central fuel injector (and associated cooling jacket) location and maximizing the size of the inlet valves for improved volumetric efficiency.

\section{Introduction}

The Spark Ignition (SI) engine remains the major source of propulsion for passenger cars on a global scale. Within Europe, the diesel remains dominant, however recent advancements in gasoline engine downsizing [1]-[3] together with the remaining concerns over relative tailpipe emissions have resulted in considerable uncertainties around the dominance of diesel in the light duty sector. As a result, there is now elevated focus upon powertrain electrification, where the "cleaner" SI engine is well suited to hybridised and electric range extender concepts foreseen to attract significant market share in the medium term [4], [5].

Despite the relative maturity of the SI engine, many of the interactions that occur during combustion are complex, with cycle-tocycle variations in the in-cylinder flow (bulk and smaller scale), spark energy, charge homogeneity (with some stratification in fuel 
and/or EGR) and flame-wall interactions and arising heat transfer [6], [7]. During combustion, the spark initiates a flame kernel between the electrodes that is initially laminar in nature, but with local turbulence very quickly serving to convect and distort the flame [8],[9]. As the flame grows progressively larger scales of turbulence are encroached, which beneficially wrinkle the flame surface, leading to a larger entrainment area [10]. Conversely, flame development slows as the walls are approached, with progressively smaller scales left available ahead of the flame and wall heat transfer effects also becoming significant. By the time the flame reaches the periphery, a considerable proportion of mass has been entrained but remains in unburned pockets behind the flame front [10]. Experimental methods to simultaneously image the flow and flame have previously been attempted but usually involve compromise in spatial or temporal resolution. For example, Ruess [11] employed PIV with simultaneous planar flame imaging via Mie scattering, but significant compromises were necessary for the seeding density which led to lack of clarity in the definition of the flame front. Elsewhere, Cairns and Sheppard [10] adopted a dual seeding approach, where planar flame images were captured at high resolution via Mie scattering (with fine particles of Titanium dioxide adopted) while larger particles (culinary white pepper) were simultaneously injected through the cylinder wall and tracked via Particle Tracking Velocimetry. The work uncovered some useful flame-flow interactions (such as the flame "pinching" the flow and accelerating existing bulk air motions), but flow tracking was sparse and not suitable to define spatial and temporal variance in turbulence (with the method also highly laborious to employ over multiple cycles). It was shown [12] that the increase in low scale high frequency turbulence would be more efficient in improving the combustion rate, thus, reducing cyclic variability. Additionally, it was presented that the moderate increase in the bulk flow motion (either tumble or swirl), with increased early flame kernel convection and higher flame wrinkling, would result in improved initial flame development and faster burning rates [13],[14]. Even then, no flow field to turbulent flame interaction was shown. Thus, it remains imperative to better understand these interacting processes, especially in the backdrop of evolving fuels with varying burning characteristics.

The adoption of ethanol has attracted renewed interest over the past decade or so, especially when produced from renewable sources. Alcohol based fuels may present one viable renewable solution, with the potential to be used in a near CO2-neutral manner through efficient conversion of biomass. The idea of using alcohol as an automotive fuel is not new [15]-[18], but only recently have such fuels begun to attract significant worldwide attention. First generation biofuels for SI applications were largely based on gasoline-ethanol blends, where current fuel quality standards typically allow between 5-10\% inclusion of ethanol within an existing

57 gasoline pool. The main exception to this is Brazil, where alcohol fuels largely produced from sugar cane are widely available in anhydrous "gasohol" up to neat ethanol form [19]. Elsewhere, gasoline containing up to 85\% ethanol ("E85") has emerged as a passenger car fuel, but so far mainly as a niche product, with flex-fuel operation still required [20]. It is still highly questionable as to whether mass conversion to fuels containing high concentrations of biofuel is practical. Production of biofuel from feedstock is 

mass-produced from alternative sources such as cellulose, algae or even recovered waste [21]-[23].

63 The lower alcohols of reduced carbon count are well suited to modern downsized SI engines, where the high latent heat of vaporization aids anti-knock performance [24],[25]. While the lower alcohols have therefore warranted significant interest, "higher" alcohols such as propanol, butanol, and pentanol have also been considered for automotive use, primarily due to their suitability for mixing within the existing gasoline pool. From a thermodynamic stance, higher alcohols generally exhibit higher calorific value (and hence better volumetric fuel consumption), better water tolerance, volatility control and lower Reid vapour pressure [26]-[30]. However, benefits in knock resistance and latent heat are typically reduced. Possible differences in the source to wheel energy consumption should also be considered if such fuels are ever to be produced on mass. In recent work, Aleiferis and co-workers [29], [31]-[33] have considered the nature of the flame propagation process with modern blended fuels. In early work employing a similar engine to that adopted here, it was observed that the flame often had a tendency to migrate towards the exhaust side of the bore, occurring regardless of fuel type. This was postulated to be associated with the hotter wall temperatures; however, flow imaging was not available to confirm the lack of bulk air motion in this region. Other more recent observations have extended to consider hydrogenated ethanol effects, where the energy to produce the fuel would be considerably reduced if increased water content could be tolerated [32]. The increase in water-in-ethanol content decreased flame wrinkling and combustion speed. The slower burning fuel iso-octane was subjected to a longer turbulent spectrum period with highest wrinkling, shape factor and flame centre total displacement of $11.33 \mathrm{~mm}$. A blend containing $84 \%$ iso-octane and $16 \% \mathrm{n}$-butanol (B16I84) in volumetric content was also affected similarly in terms of both flame stretch toward the exhaust and flame centre total displacement of $10.7 \mathrm{~mm}$. Ethanol as the fastest burning fuel was more resistant to flame centre displacement, with the lowest shape factor and highest flame speed. The aim of the currently reported work was to study flame propagation and distortion for different fuels where both flame and flow data are available. This involved flow imaging with PIV at a horizontal imaging plane close to TDC (10 $\mathrm{mm}$ below the fire face) throughout the compression stroke $\left(30^{\circ}, 40^{\circ}, 90^{\circ}\right.$ and $180^{\circ} \mathrm{CA}$ BTDC). High-speed natural light (chemiluminescence) imaging with simultaneous in-cylinder pressure data measurement and analysis were also then used to understand the fundamentals of flame propagation for ethanol, iso-octane, and a specific butanol blend.

\section{Experimental Arrangement}

87 A customized single cylinder DISI optical engine was used in this study. The basic engine specifications are presented in Table 1,

88 with corresponding optical engine schematics presented in Figure 1. The cylinder head had a pent-roof combustion chamber design 
production and installed following manufacture guidelines [34]. The engine was fitted with a "neutral" intake port, without the

91 sharp inner corner radius associated with high tumble engine designs and the four valves were operated by double overhead camshafts housed in an aluminum casing. The bottom-end was based on a Ricardo Hydra, mounted on a 30kW Cussons test bed with integrated oil and coolant control $\left( \pm 2^{\circ} \mathrm{C}\right.$ tolerance). The hydra was fitted with a customized cast iron block, wet liner, and a Bowditch piston as indicated. The Bowditch type piston allowed for a $45^{\circ}$ mirror to be placed inside the hollow core providing optical access to the combustion chamber through a quartz piston crown. The extended piston was made of aluminum. PTFE compression rings lubricated with grease. The flat-topped piston crown quartz window had 55 mm diameter, resulting in approximately $50 \%$ bore covered area. Figure 2 shows the visible area provided by the optical window and the positioning of the valves. A sandwich plate was designed to join the cylinder head and the extended block with two additional side windows $(21 \mathrm{~mm}$ height) providing additional optical access to the combustion chamber. The windows were used to guide the PIV laser light through the combustion chamber at the piston position of $30^{\circ} \mathrm{CA}$ BTDC firing. The laser sheet was aligned horizontally at $5 \mathrm{~mm}$ above the optical piston and $10 \mathrm{~mm}$ below the spark plug. A key limitation of the design was the enlargened top land volume as illustrated in Figure 1. This resulted in relatively high blow-by and slow end of mass burning as fuel-air charge returned to the main chamber during the power stroke.

\begin{tabular}{|l|l|}
\hline Displaced volume & $447 \mathrm{cc}$ \\
\hline Stroke & $89 \mathrm{~mm}$ \\
\hline Bore & $80 \mathrm{~mm}$ \\
\hline Compression ratio & $8.67: 1$ \\
\hline Inlet vales diameters & $29.5 \mathrm{~mm}$ \\
\hline Exhaust valves diameters & $21 \mathrm{~mm}$ \\
\hline Valve lift & $9 \mathrm{~mm}$ \\
\hline Cam duration (Exhaust, Intake) & $220^{\circ} \mathrm{c}$.a. (end of ramp) \\
\hline EMOP & $265^{\circ}$ ATDC (compression) \\
\hline IMOP & $455^{\circ}$ ATDC (compression) \\
\hline Engine Coolant temperature & $90^{\circ} \mathrm{C}$ \\
\hline Injection timing & $300^{\circ} \mathrm{CA}$ BTDC firing \\
\hline
\end{tabular}
a PowerStar4 double ended air driven pump with an amplification ratio of 64:1. Using an air pressure regulator, the injection pressure for the tests was set to 100 bar. The pressure variation in the fuel rail was measured to be \pm 2 bar at 100 bar fuel pressure. 


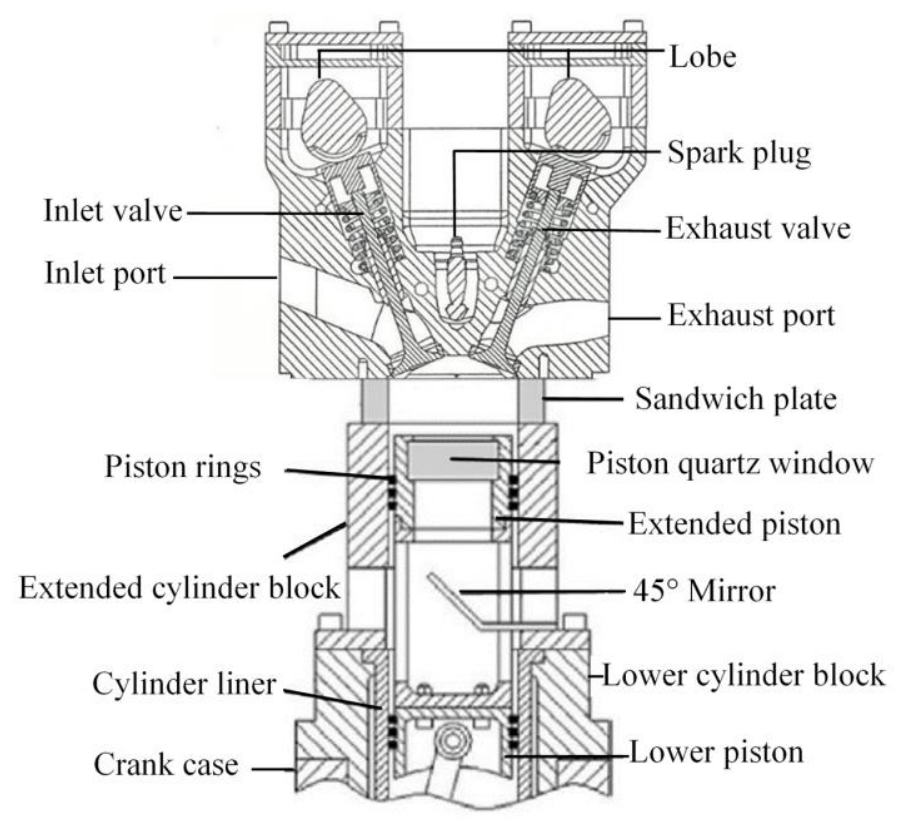

111 Three fuels were investigated: Iso-octane, anhydrous ethanol, and B16I84. The butanol was blended in this manner to represent a fuel with oxygen content equivalent to E10 fuel. It seems likely that butanol will only ever be adopted as a low volume blending 113 agent (being of higher carbon count than ethanol, with increased production energy and arguably less advantage in terms of anti114 knock additive in future, boosted SI engines). Some of the key properties of the component fuels are set out in Table 2. Ethanol as 115 the fastest fuel required an $\mathrm{MBT}$ of $40^{\circ} \mathrm{CA} \mathrm{BTDC}$. It was decided to use a fixed spark timing of $40^{\circ} \mathrm{CA} \mathrm{BTDC}$ for all the fuels. This was to ensure that, nominally, the same flow field conditions existed on average at ignition timing for all tests, however it is important to acknowledge differing optimum ignition timings for the two primarily hydrocarbon fuels as there will be more heating of the unburned charge due to the combined expansion of the burned gas and the compression due to piston motion. This could potentially accelerate their flames and give different results. The laminar burning velocities were taken from [35], [36], being obtained at stoichiometric conditions at $373 \mathrm{~K}$ and $10 \mathrm{bar}$ (considered to be representative of typical in-cylinder conditions under part load). It is apparent that differences amongst fuels at high pressure are quite small. Although experimental uncertainties of the order $1 \mathrm{~cm} / \mathrm{s}$ typically exist, there is a decrease in burning velocity with decreasing pressure, increasing temperature, as well as with increasing carbon chain length for the alcohols. During the firing experiments typical start-of-injection timing at $60^{\circ}$ Crank Angle (CA) after intake Top Dead Centre (ATDC) was considered for 'homogeneous' mixture preparation and pulse width duration of $0.52 \mathrm{~ms}, 0.78 \mathrm{~ms}$ and $0.5 \mathrm{~ms}$ were used for iso-octane, ethanol and B16I84 respectively, in order to attain stoichiometric combustion at the same throttle position the fuelling was monitored using a Horiba-mexa-110 $\lambda$ air/fuel ratio measurement system with commercial wideband Lambda sensor. The correct $\mathrm{C} / \mathrm{H} / \mathrm{O}$ ratio was inputted in the equipment for each fuel. 


\begin{tabular}{|l|l|l|l|}
\hline Fuel parameters & Iso-Octane & Ethanol & n-butanol \\
\hline Chemical formula & $\mathrm{C} 8 \mathrm{H} 18$ & $\mathrm{C} 2 \mathrm{H} 5 \mathrm{OH}$ & $\mathrm{C} 4 \mathrm{H} 9 \mathrm{OH}$ \\
\hline Density $20^{\circ} \mathrm{C}\left[\mathrm{g} / \mathrm{cm}^{3}\right]$ & 0.69 & 0.79 & 0.81 \\
\hline Density $80^{\circ} \mathrm{C}\left[\mathrm{g} / \mathrm{cm}^{3}\right]$ & 0.64 & 0.73 & 0.76 \\
\hline Latent heat $(\mathrm{at} \mathrm{T}$ boil $[\mathrm{kJ} / \mathrm{kg}])$ & 272 & 855 & 584 \\
\hline Latent heat $\left(25^{\circ} \mathrm{C}\right)[\mathrm{kJ} / \mathrm{kg}]$ & 300 & 874 & 669 \\
\hline Gravimetric $\mathrm{LHV}[\mathrm{MJ} / \mathrm{kg}]$ & $44.6^{\mathrm{b}}$ & $26.9^{\mathrm{b}}$ & $33.9^{\mathrm{b}}$ \\
\hline Volumetric $\mathrm{LHV}[\mathrm{MJ} / \mathrm{l}]$ & $30.8^{\mathrm{b}}$ & $21.3^{\mathrm{b}}$ & $27.5^{\mathrm{b}}$ \\
\hline Flash point $\left[{ }^{\circ} \mathrm{C}\right]$ & -12 & 12 & 30 \\
\hline Stoichiometric AFR & 15.1 & 9 & 11.1 \\
\hline Mole ratios, $\mathrm{H} / \mathrm{C}$ & 2.25 & 3 & 2.5 \\
\hline Mole ratios, O/C & 0 & 0.5 & 0.25 \\
\hline Laminar burning velocity, [m/s] & $0.36^{\mathrm{c}}$ & $0.42^{\mathrm{c}}$ & $0.42^{\mathrm{c}}$ \\
\hline RON & 100 & $107^{\mathrm{d}}$ & $96^{\mathrm{d}}$ \\
\hline Injection duration, $[\mathrm{ms}]$ & 0.52 & 0.78 & 0.5 \\
\hline
\end{tabular}

a) If not specified, data taken from product data sheets.

c) Taken from [35], [36]

133 d) Taken from [38].
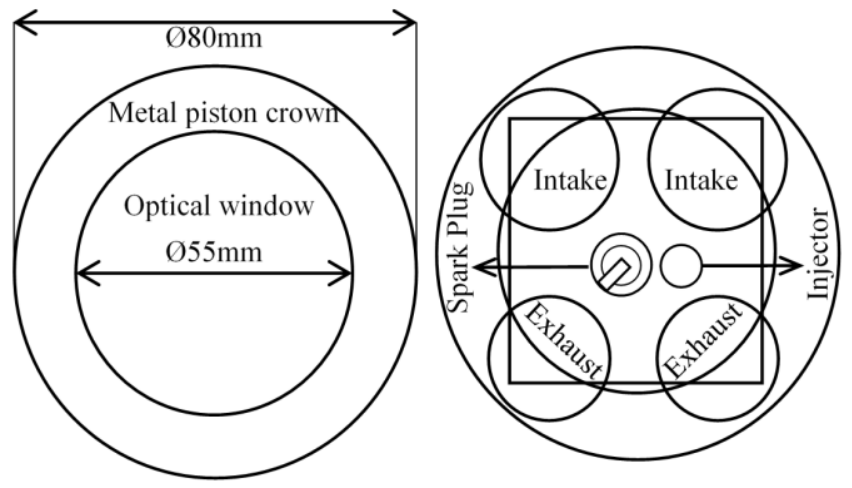

Figure 2. Combustion chamber and Piston crown

\section{PIV experimental implementation}

137 The laser unit used for the PIV experiments was a NANO L 135-15 PIV laser supplied by Litron Lasers. The laser unit was powered by an LPU 450 power station configured to drive two laser units with a $450 \mathrm{~W}$ combined throughput. The laser head consisted of two $1064 \mu \mathrm{m}$ laser units, half wave plates, mixing and steering polarizers and a harmonic generator. The laser head supplied $532 \mu \mathrm{m}$ laser beams with up to $136 \mathrm{~mJ}$ laser pulse energy under a $160 \mu$ s optimized Q-switch delay. The images of flow with seeding particles were captured using a Dantec Dynamic FLOWSENSE 4M camera system with an ICCD camera of 2048x2048 pixels, which had

142 a minimum inter-frame time of 200ns. The lens used for the PIV test was an UV-Nikkor 60 mm lens. A 532nm narrow band filter 
formed to ensure spread across the full horizontal imaging plane. The laser sheet was aligned $5 \mathrm{~mm}$ above the optical piston and $10 \mathrm{~mm}$ below the spark plug, as close as possible to TDC (at $30^{\circ} \mathrm{CA}$ BTDC). This was considered to be a limitation of the engine design, as the flow immediately around the spark plug remained out of the image. The ICCD camera was positioned in the case that images were captured through the $45^{\circ}$ mirror via the Bowditch optical access. Figure 3 presents the experimental arrangement of the PIV laser, mirror, camera and optical apparatus.

149 A non-toxic, non-corrosive, non-abrasive, non-volatile and chemically inert vegetable oil (density $910 \mathrm{~kg} / \mathrm{m} 3$ ) was selected as the PIV seeding particle. Its properties enabled it to provide minimum drag impact and yet scatter enough light for the PIV measurements. A 10F03 seeding generator supplied by Dantec Dynamics was used. The equipment was set to supply seeding flow with an average droplet size of Sauter Mean Diameter (SMD) $2 \mu \mathrm{m}$ to $3 \mu \mathrm{m}$ up to a pressure of 3 bar. The seeding was supplied downstream of the throttle plate, the frequency and amplitude response of a particle of that density and size was calculated on the basis of its relaxation time [39] and it was found to be able to respond appropriately to fluctuations up to a range of $\sim 5-7 \mathrm{kHz}$.

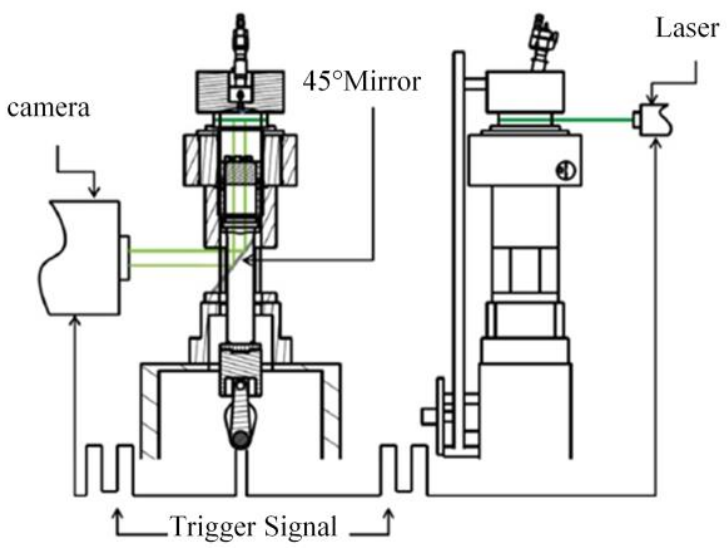

The PIV processing was undertaken using the commercial platform Dynamic Studio. A MATLAB code was developed to post process and calculate the average cycle images with arrow size scaled in respect to velocities using a quiver function. A detailed explanation of this PIV function has previously been well presented in [40] so only a brief explanation will be provided here. The images with the flow seeding particle position information were divided into a number of square interrogation areas depending on many factors. The velocity vector evaluation of each interrogation area was calculated using the cross-correlation method. For this PIV experimental setup, a 32x32 pixels interrogation area was used combined with the Gaussian algorithm, which corresponds to a spatial resolution of $1.8 \mathrm{~mm} \times 1.8 \mathrm{~mm}$. The PIV was measured at compression stroke crank angles of $30^{\circ}, 40^{\circ}, 90^{\circ}$ and $180^{\circ} \mathrm{CA}$

164 BTDC for a low load engine operating condition at $1500 \mathrm{rpm}$ ( 0.5 bar absolute plenum pressure $)$. Figure 2 shows the top view indicating optical access through the piston crown (inner circle) and PIV image size (rectangle). 
The turbulence intensity was calculated from PIV images as the Root Mean Square (RMS) of the turbulence velocity and the mean

167 velocity. Since PIV is a 2-D technique, the turbulence intensity in the co-ordinate that was into the plane of measurement was

168 estimated as the average of the turbulent intensities in the other two directions. Turbulence intensity energy was calculated

169 according to the following formula:

$170 \quad I=\frac{u^{\prime}}{U}$

\section{$171 \quad$ High speed imaging}

172 A NAC MEMRECAM fx 6000 high speed video camera coupled to a DRS Hadland Model ILS3-11 image intensifier was used to

173 record all optical data. The camera was synchronized with a DAQ to record images simultaneously with the pressure data. The

174 camera was set to record $6000 \mathrm{fps}$ resulting in time-resolved images every $1.5 \mathrm{CAD}$ at a resolution of $512 \times 384$ pixels. In line with

175 industry practice, 300 thermodynamic results were obtained with each run, with 60 optical cycles obtained due to camera internal

176 memory limitation. This was considered an acceptable compromise as both this work and others have shown that 50 cycles may

177 bottom out the bulk of variation [9].

178 The lens used for the high speed imaging test was an UV-Nikkor $105 \mathrm{~mm}$ lens. An intensifier intensity sweep was undertaken to

179 determine the optimal compromise between image intensity and noise level. It was concluded that $80 \%$ of the maximum intensifier

180 capacity was required to provide sufficient flame intensity under the stoichiometric conditions examined (determined by evaluating the computed flame radius in a repetitive manner to ensure repeatability).

\section{$182 \quad$ Flame image processing}

183 Once the combustion cycles were captured as a concurrent set of images, they were downloaded in TIFF format. An in-house 184 MATLAB script was developed to batch process the files, converting each TIFF to a black and white image. A dynamic masking 185 process was applied to remove any 'halo' from the bore. Finally, the image was inverted into black and white and the visible area circle was applied. These stages are laid out visually in Figure 4.

187 To calculate the enflamed area of each image, the matrix that forms the binary image was simply summed to a single number that

188 represented the area of the flame in square-pixels. Since the diameter of the imaging area was known (55mm) in terms of both the number of pixels in the image and the real diameter in millimetres, the area in square pixels could be easily converted into squaremillimetres. 


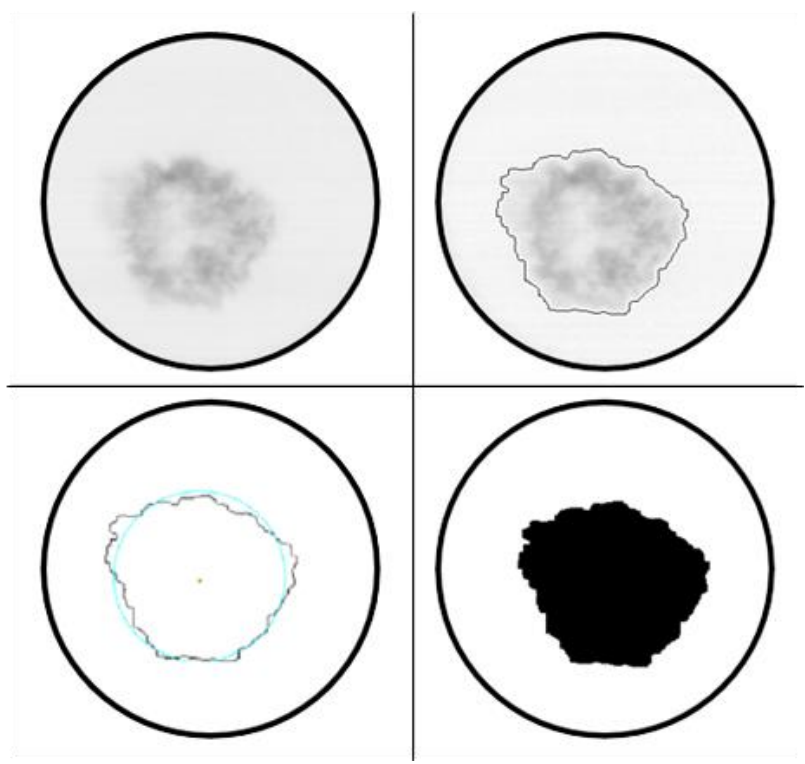

Figure 4. Illustration of the flame image processing procedure.

The flame centroid was identified by locating the point at which a centre of "mass" would be situated considering the enflamed area as a solid object. For the finite set of pixels $\left(p_{x}\right)$ throughout the image, the centroid is:

$c=\sum \frac{p_{x}}{k}$

where $\mathrm{k}$ is the number of pixels selected in the image and $p_{x}=\left(x_{i}, y_{i}\right)$ the Euclidean co-ordinates of the pixels.

The flame radius was calculated based on a method considering that the amount of unburned charge encompassed by a circle with such radius would be equal to the amount of burned charge [9]. Figure 4 shows both the best-fit circle (Cyan) and the flame contour (Black) for an individual image in a cycle with flame perimeter and area also shown. To define the influence of the bulk air motion, the shape factor was also calculated as the ratio of the actual flame perimeter length to that of a circle encapsulating an equivalent area [9]. as sum of the turbulent entrainment velocity and the velocity at which the unburned gas is pushed away by compression due to piston motion and the expanding burned gas. 


\section{Computational Fluid Dynamics}

\section{$211 \quad$ 1-D modelling}

212 A 1-D modelling approach was adopted using the commercial modelling package (GT-Power). This simulation was required to

213 define the boundary conditions for CFD cold flow. The model was constructed to accurately represent the test engine, with engine

214 geometry and thermodynamic input data available. The model was fed with the measured average in-cylinder pressure data, with

215 the combustion modelled using the well-known Wiebe function. Heat transfer was estimated using the Woschni correlation, albeit

216 inevitably incurring some additional error due to the fact that the engine was fitted with a glass piston. Overall an acceptable level

217 of correlation was achieved, with volumetric efficiency and engine load matched within $<3 \%$.

\section{3-D CFD Modelling}

219 A model of the optical engine was created in the commercial CFD code ANSYS (ICE). The mesh dynamics was handled by ANSYS

220 mesh. The model consisted of approximately 1,200,000 elements including 4 Node Linear Tetrahedron, 8 Node Linear Hexahedron,

2216 Node Linear Wedge (Prism) and 5 Node Linear Pyramid. The global cell size was of the order of 0.5 mm. The model domain

222 started at the intake port/manifold interface and extended to the exhaust port outlet. The grid dependency study was examined with

223 testing the solution in a finer mesh size and very similar results with less than $3 \%$ difference were achieved. As mentioned in the previous paragraph, a mass flow boundary condition taken from GT-Power model was applied at the inlet runner and a static pressure boundary was applied at the exhaust outlet. The k-epsilon model is an industry standard and may be widely used by the industry due to its simplicity, but it is not robust enough for the prediction of anisotropic flows [41]. Therefore, the k-epsilon RNG model [11] was applied in an initial attempt to compare the effect of the turbulent model on the CFD results. The k-epsilon RNG model [42],[43] uses an extra term dependent on the strain invariant, thus incorporating the influence of additional strain rates, more promising to solve second-order discretization as it attempts to account for the different scales of motion and has the ability to capture flow effects that the standard k-epsilon may not capture. A time-step of $1^{\circ} \mathrm{CA}$ was used throughout the analysis, except at valve opening events where $0.5^{\circ}$ was necessary. Ideal gas properties for air were used throughout the simulation.

\section{Flow and flame imaging results}

233 It is crucial to have statistically robust calculations when considering a highly turbulent environment and the associated cyclic

234 variations in the flow within an IC engine. In order to quantify the 'ensemble mean' flow field and turbulent flow parameters, 1500 235 cycles were selected at $30^{\circ} \mathrm{CA}$ BTDC and randomly (using MATLAB rand code) divided into 15 batches, with each batch containing 100 cycles. Figure 5 indicates the computed turbulence intensity and average velocity for these batches on a primary $\mathrm{Y}$ axis and secondary Y axis respectively. 


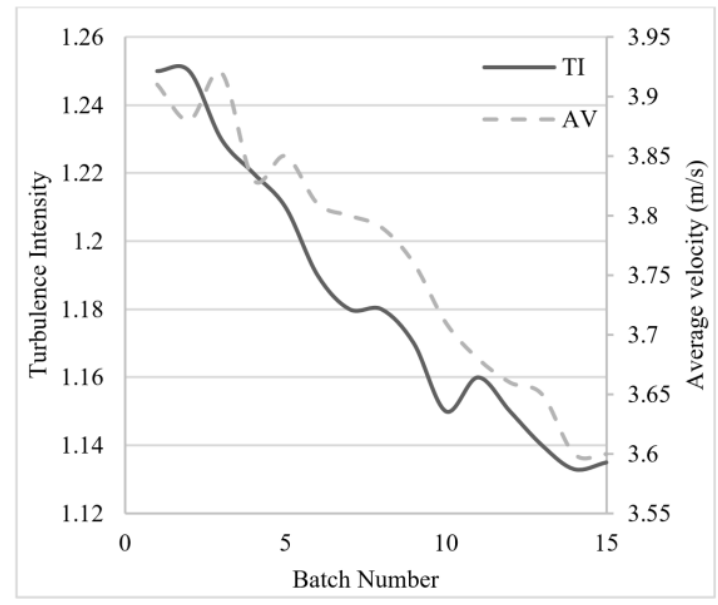

Figure 5. Effect of number of batches (100 Cycles each) on measured velocities (100-1500 cycles).

242 Turbulence intensity data presented herein are the RMS of the deviations measured from an average velocity at a $32 \times 32$ pixel

243 "point" averaged over 800 cycles calculated in the MATLAB code. The points in each quadrant are averaged to produce one value 244 representing that zone.

245 Understanding the flow fields between $180^{\circ} \mathrm{CA}$ BTDC and $30^{\circ} \mathrm{CA}$ BTDC under motoring conditions was considered important to try and understand the evolution of the bulk air motions leading up to the ignition events. Caution is required, as the imaging plane was located somewhat below the spark plug. However, it was postulated that any residual bulk air motions could be as large as the chamber itself. If any such scales existed in the tumbling plane then these should have also manifested as higher velocities in the horizontal plane (given the rotational nature of the tumble). Unfortunately, flow measurements were not possible at the very end of compression from $30^{\circ} \mathrm{CA}$ BTDC until TDC as at any crank angle after $30^{\circ} \mathrm{CA}$ BTDC the laser sheet was covered by the 251 piston.

\section{PIV ON HORIZONTAL PLANE}

255 To understand the behavior of the in-cylinder bulk flow, PIV images were divided into four zones (denoted I1, I2, E1, E2) with the 256 inlet valves on the top and exhaust valves on the bottom side of the image as shown in Figure 6 . Vector fields between $180^{\circ} \mathrm{CA}$

257 BTDC and $30^{\circ} \mathrm{CA}$ BTDC are from the period that the air is being compressed in the cylinder with both valves closed until top 258 dead centre. The gas velocity range during this period was between $0-20 \mathrm{~m} / \mathrm{s}$.

259 Shown in Figure 7 a) are mean velocity fields compared with the corresponding k-E RNG CFD result. In general, the air flow 260 structure visible from the optical window of the piston crown follows coherent discernable patterns that visually correlate reasonably well with the CFD results. The highest turbulence intensity in each zone presented in Table 3 was I1=3.24, I2=3.19, 


\begin{tabular}{|l|l|l|l|l|}
\hline & $180^{\circ} \mathrm{BTDC}$ & $90^{\circ} \mathrm{BTDC}$ & $40^{\circ} \mathrm{BTDC}$ & $30^{\circ} \mathrm{BTDC}$ \\
\hline Zone $\mathrm{I}_{1}$ & 1.24 & 1.20 & 1.17 & 1.12 \\
\hline Zone $\mathrm{I}_{2}$ & 1.19 & 1.18 & 1.20 & 1.17 \\
\hline Zone $\mathrm{E}_{1}$ & 1.22 & 1.16 & 1.21 & 1.11 \\
\hline Zone $\mathrm{E}_{2}$ & 1.13 & 1.17 & 1.18 & 1.14 \\
\hline
\end{tabular}

Figure 7 b) displays the vector velocity fields at $90^{\circ} \mathrm{CA}$ BTDC, where all divided zones generally exhibited higher velocity when compared to $30^{\circ}$ or $40^{\circ} \mathrm{CA} \mathrm{BTDC}$. Overall, the measured and predicted turbulence intensities computed in each zone were in good agreement. Shown in Figure $7 \mathrm{c}$ ) is the flow field velocity at $40^{\circ} \mathrm{CA}$ BTDC, which generally exhibited motion towards the centre of the piston below where the spark plug was located, with slightly higher overall turbulence intensity in comparison to $30^{\circ} \mathrm{CA}$ BTDC as shown in Figure $7 \mathrm{~d}$ ). The velocity ranges for $30^{\circ}$ CA BTDC were between $0-11 \mathrm{~m} / \mathrm{s}$ with an average value of $3.6 \mathrm{~m} / \mathrm{s}$.

271 The main overall visible structure is a large flow going toward the central point nominally below the spark plug. It can be seen that

272 in each zone the values for turbulence intensities were very close, which emphasizes the fact that there was no bulk flow motion

273 toward any side of the piston. This fact can also be seen within the CFD result although some caution is required given the idealized

274 nature of the modelling approach.

275 Comparing the turbulence intensity and average velocity in each zone indicates slightly higher turbulence intensity on the right side of the piston crown (I2, E2), with the bulk flow motion heading towards the centre of the piston with no apparent complementary bulk air motion toward the exhaust. Again this was also in good agreement with the idealized CFD result.

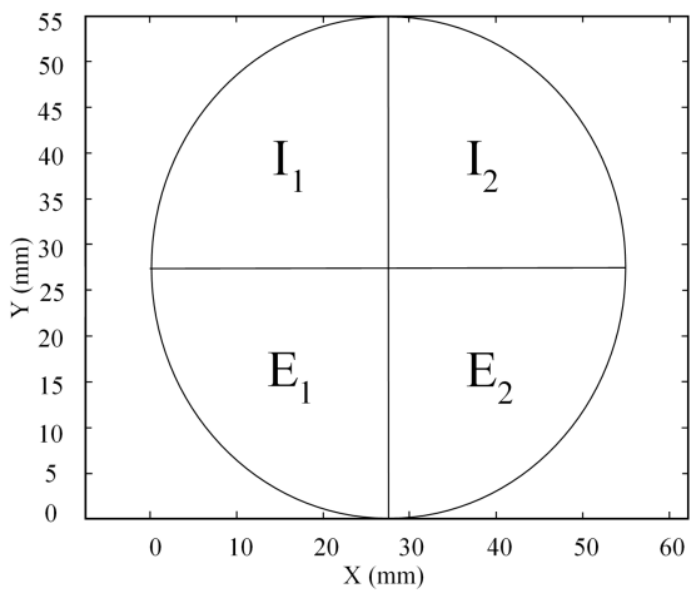 \\ 279}




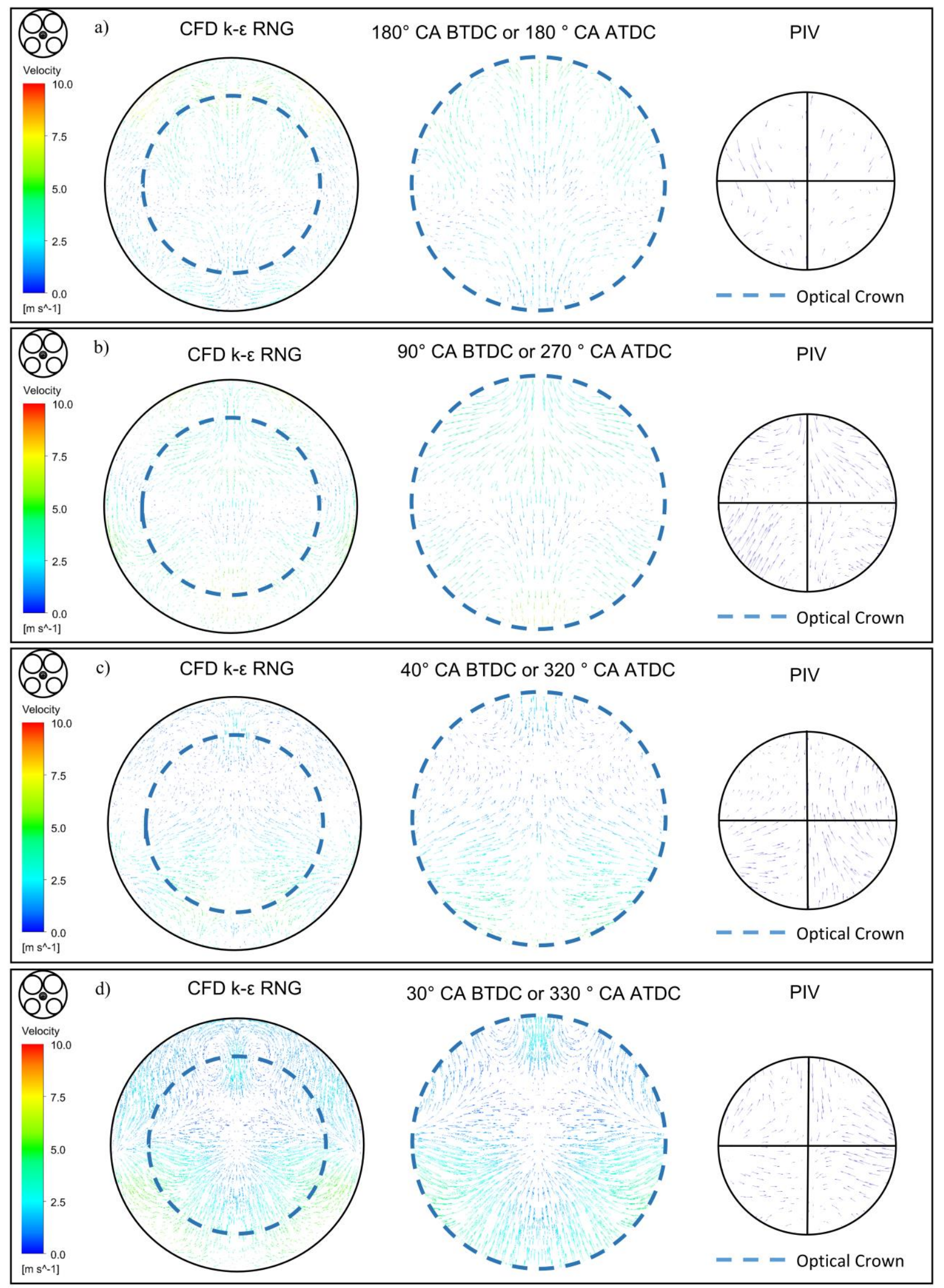




\section{Cycle selection}

282 In order to compare the cyclic variations and combustion characteristics of the fuels, a procedure was adopted to allow selection of real cycles representative of typical fast, mean and slow flame development events. When examining in-cylinder pressure data alone, with a sample size of 300 cycles it was generally observed that no single real cycle would exhibit in-cylinder pressure development identical to that of the arithmetic mean pressure profile computed over the data set. This observation is in good agreement with the prior related work of Moxey [9],[30]. Hence it was crucial to manually select a real cycle whose pressure development was closest to the averaged cycles. Set out in Figure 8 is an example data set for the pure ethanol case (Minimum spark advance for Best Torque (MBT) spark timing at $40^{\circ} \mathrm{CA}$ BTDC, $\lambda=1.0$ ) with the mean case superimposed. The selected characteristic slow and fast cycle were those nearest the computed pressure data that was two standard deviations above or below the mean pressure profile, with the achieved upper and lower (or faster and slower) fits marked with the colored dashed lines in nearest cycles.

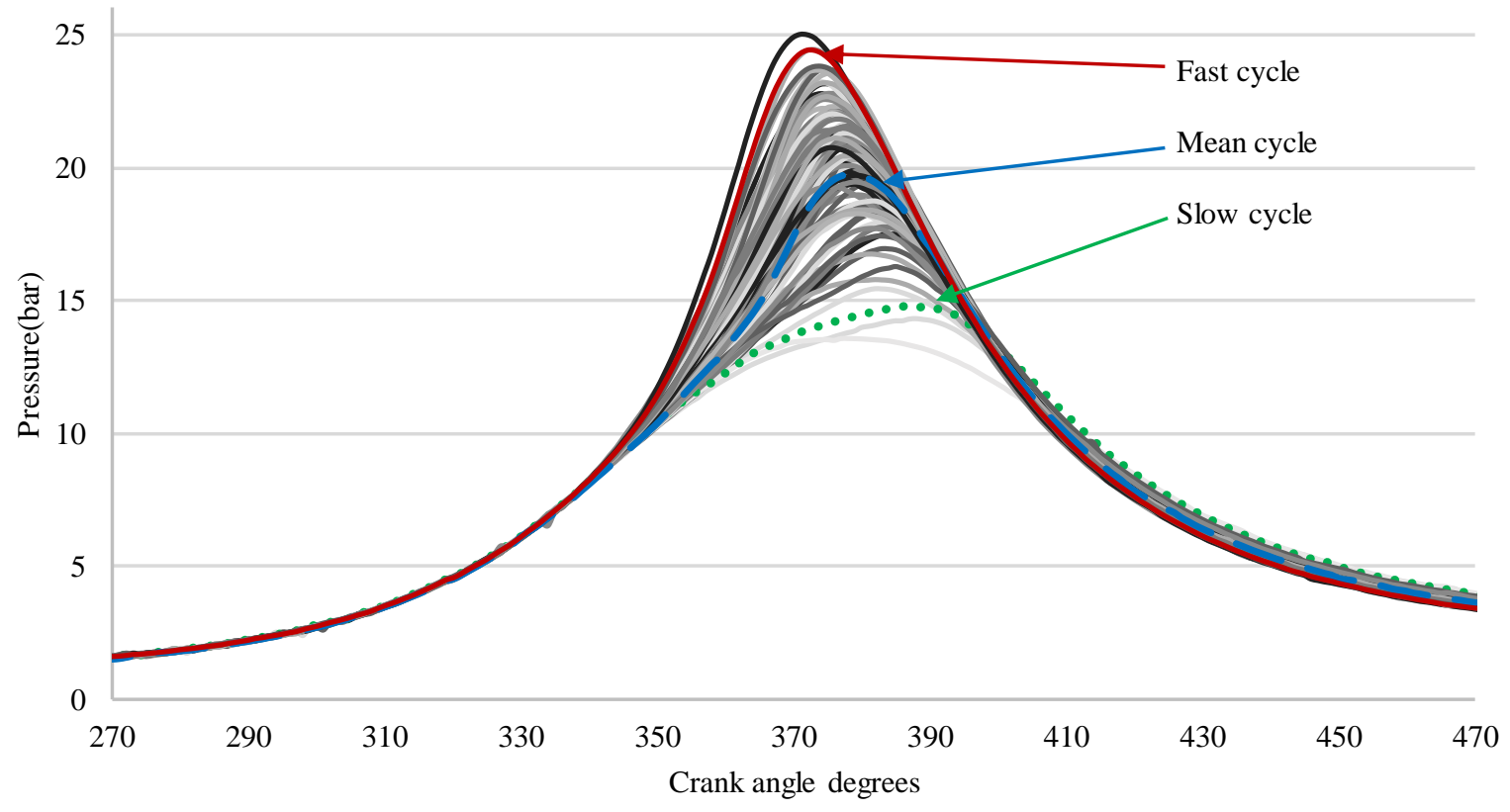

The associated load and combustion stability for the fixed spark timing at $40^{\circ} \mathrm{CA}$ BTDC (which corresponded to MBT for the fasted burning pure ethanol fuel) are shown in Figure 9 in terms of Net IMEP and combustion stability values from a cycle closest across the full 300 cycles, as the heating value and the injected mass are not the same for the three fuels, the net IMEP is also normalized with the input energy. The spark timing was fixed at the MBT value for the fastest fuel to avoid any over-advancement. 
299 Presented in Figure 10 are the heat release rate values for 3 fuels, indicating pure ethanol as the fastest burning fuel and iso-octane

300 as the slowest fuel.

301

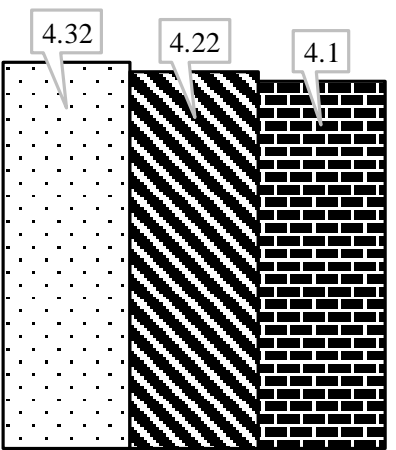

Net IMEP (bar)

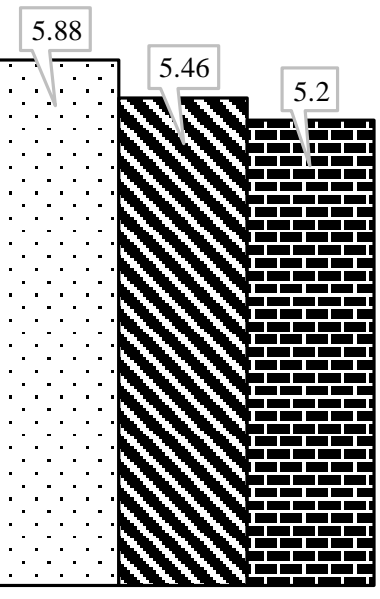

Net IMEP / Input energy

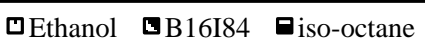




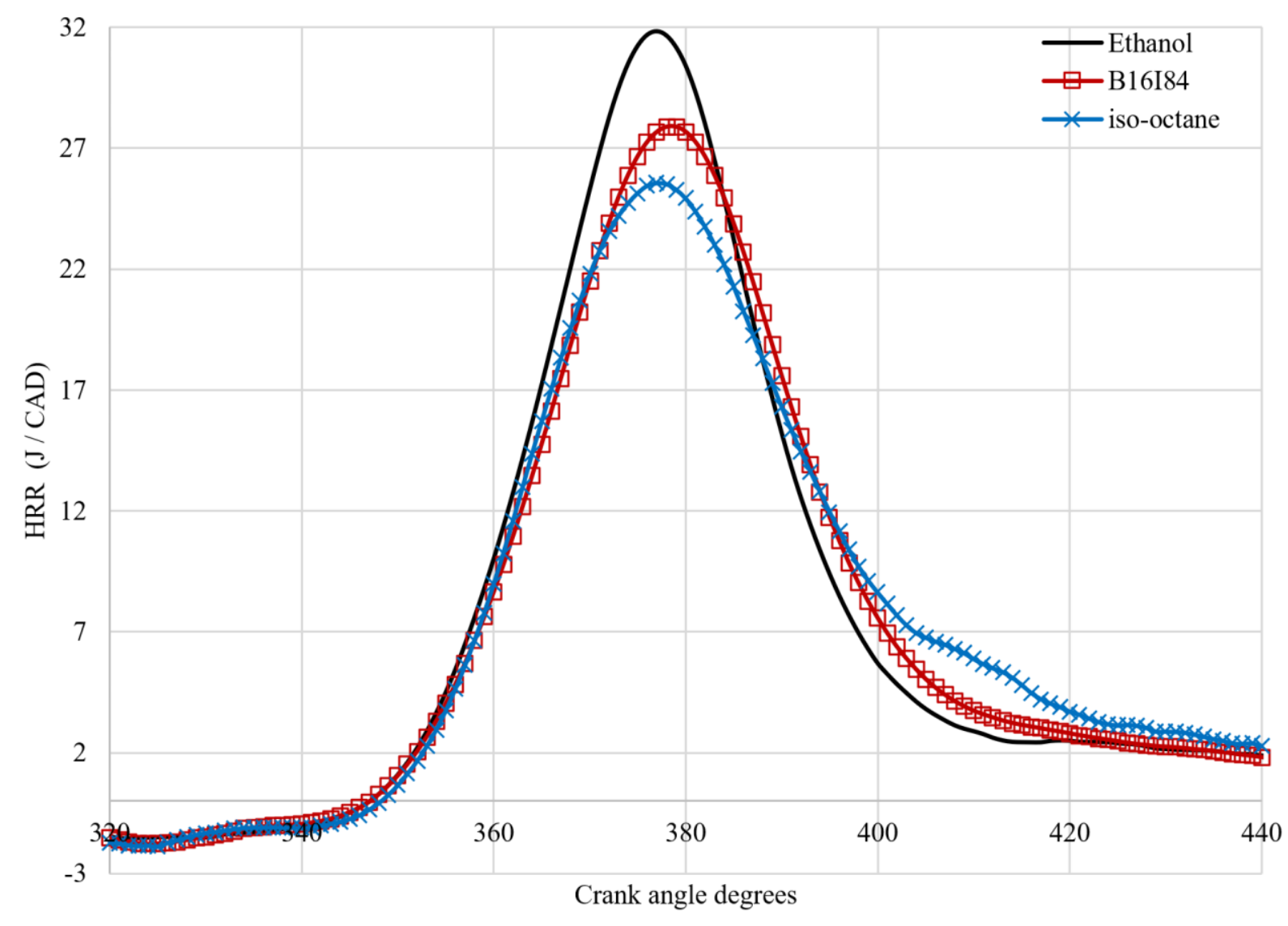

Figure 10. 300 cycles average heat release rate for all fuels (Fixed spark timing).

305 Presented in Table 3 are the key mean combustion parameters for Ethanol, Iso-octane and the B16I84 blend for 300 cycles. Ethanol exhibited a maximum pressure of 20.2 bar that was approximately $10 \%$ higher than the other two fuels. As the fastest burning fuel, it was noted to reach the crank angle timing of maximum pressure and crank angle of $50 \%$ mass fraction burned sooner, with the lowest CA_Pmax and CA50 values compared to Iso-octane and the B16I84 blend.

\begin{tabular}{|l|l|l|l|}
\hline Parameter & Ethanol & B16I84 & Iso-octane \\
\hline Pmax & $20.24 \mathrm{bar}$ & $18.52 \mathrm{bar}$ & $18.17 \mathrm{bar}$ \\
\hline CA_Pmax & $15^{\circ}$ ATDC & $17^{\circ}$ ATDC & $17^{\circ}$ ATDC \\
\hline CA50 & $6^{\circ}$ ATDC & $7^{\circ}$ ATDC & $10^{\circ}$ ATDC \\
\hline $0-10$ MFB duration & $12 \mathrm{CAD}$ & $13 \mathrm{CAD}$ & $14 \mathrm{CAD}$ \\
\hline $10-75$ MFB duration & $16 \mathrm{CAD}$ & $18 \mathrm{CAD}$ & $20 \mathrm{CAD}$ \\
\hline
\end{tabular}

310 Set out in Figure 11_is a comparison of the in-cylinder pressure data for the mean, fastest and slowest cycles for each fuel under

311 fixed spark timing of Ethanol at MBT. Here the small differences observed in Figure 12 for the mean flame development become

312 more pronounced, where the slower burning B16I84 and iso-octane cases presented wider bands of in-cylinder pressure 


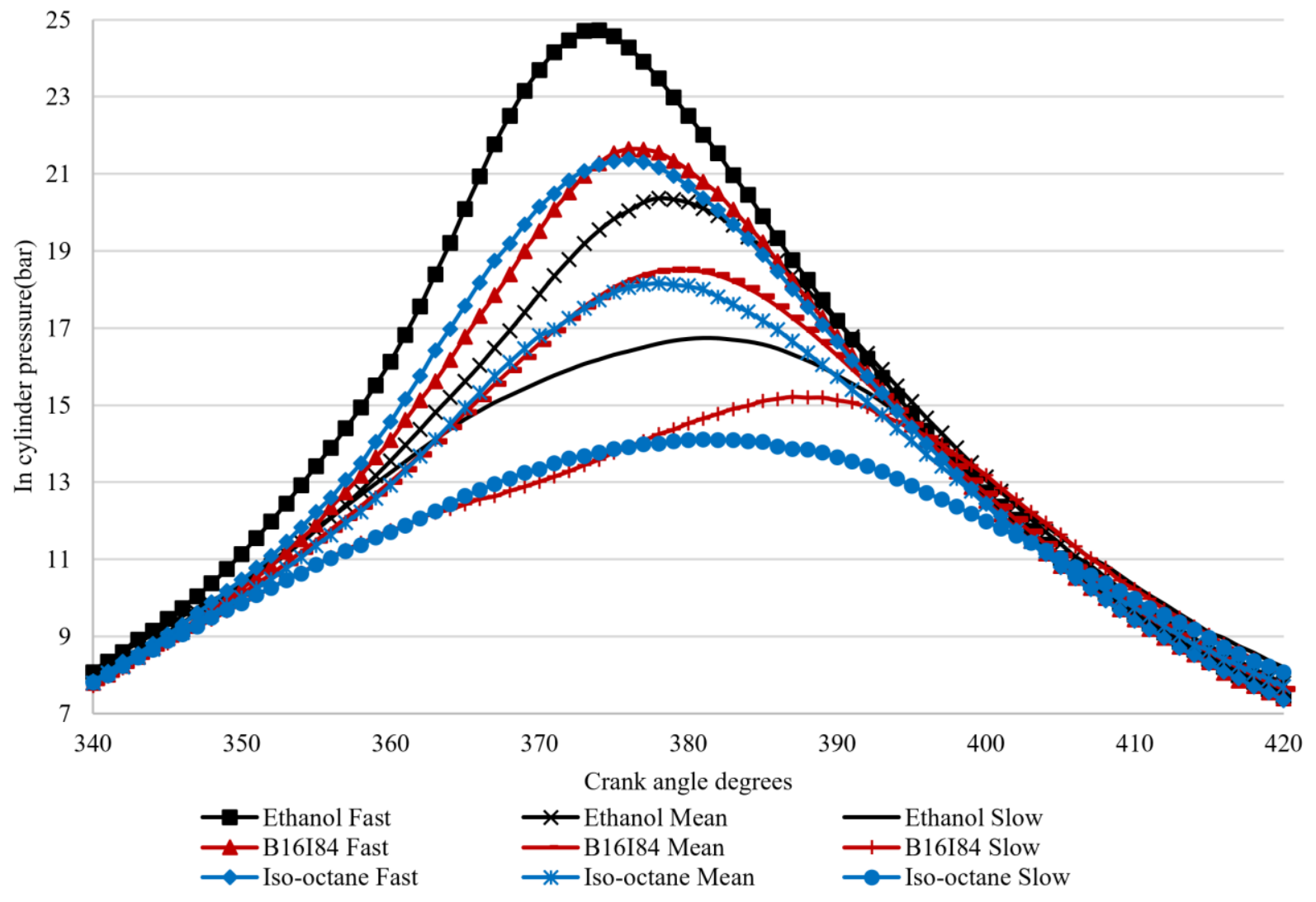




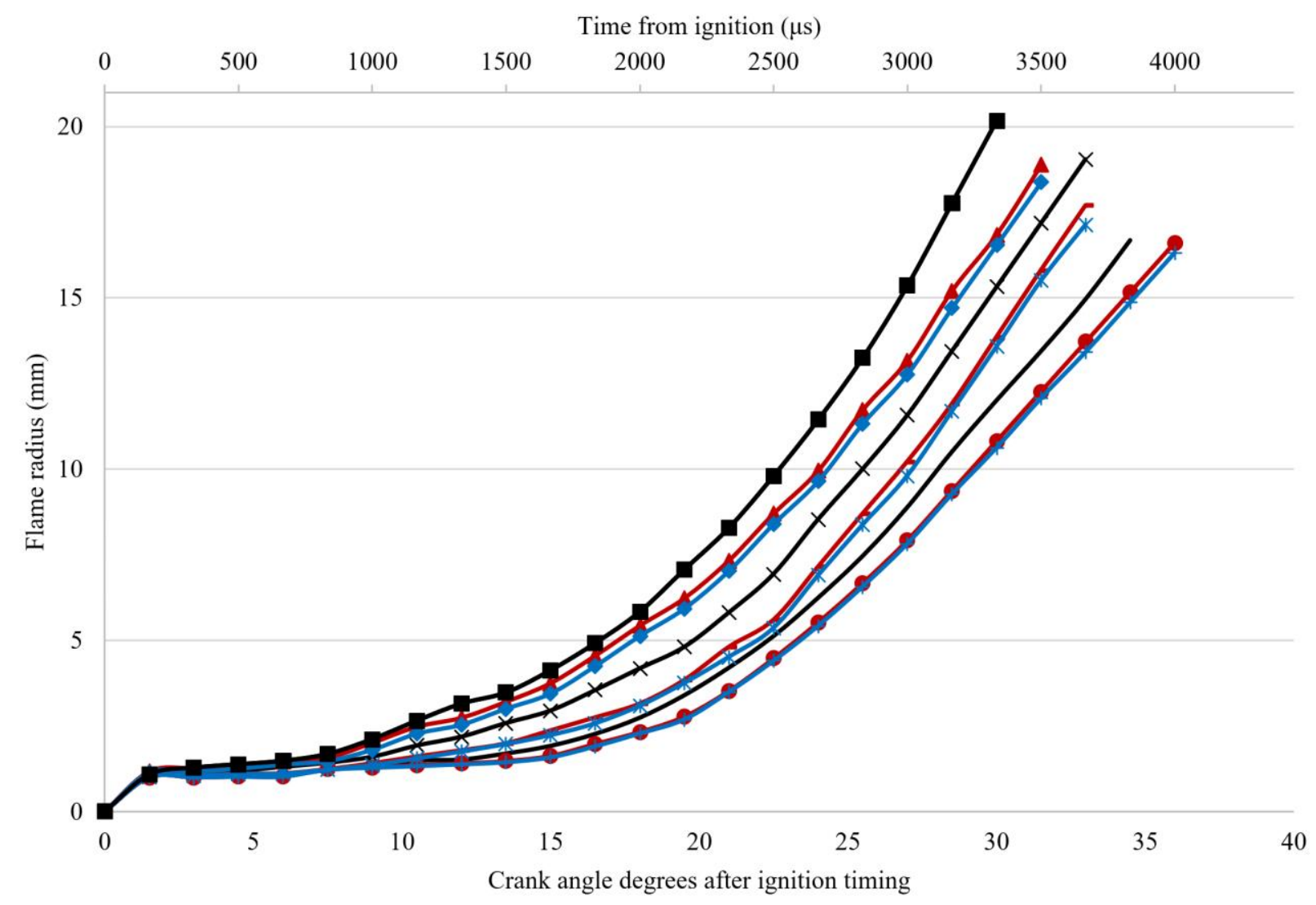

319

320

Figure 12 Flame radius for the "mean" visual cycles and relevant fastest and slowest cycle (60 cycles). 


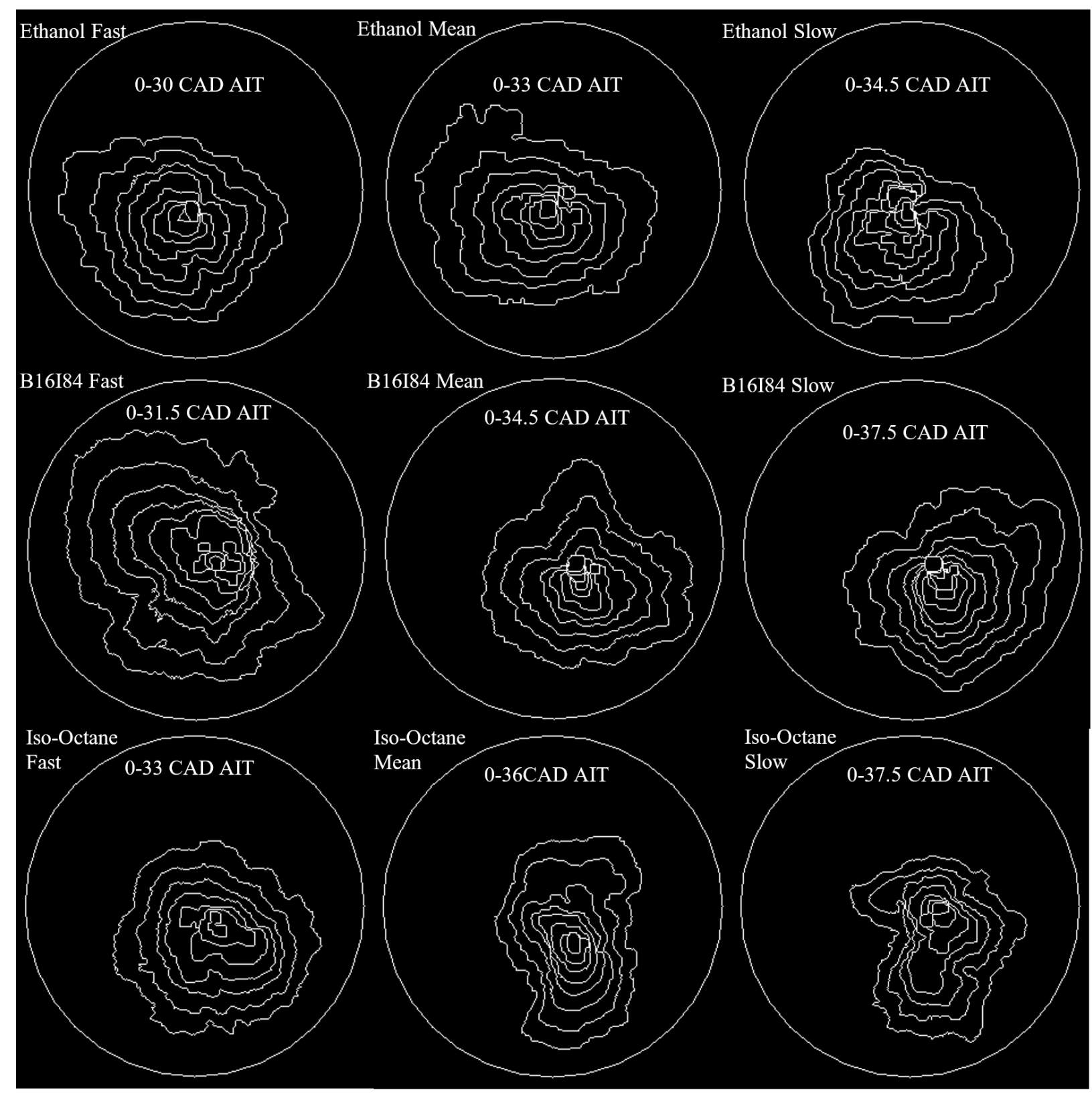

323 Figure 13. Individual Flame contours of fastest slowest and mean cycles, starting from ignition until one contour before the optical window was

324 approached in every 3 intervals.

325 Individual fast, mean and slow flame cycles were selected to understand minimum centroid displacement; as centroid displacement

326 would compromise the comparison of fuels with partial optical access (as the flame contour reaches the piston window earlier if

327 the centroid is going toward any side of the piston). To verify the synchronized pressure and computed flame radius from in-house

328 Matlab script, each individual cycle was compared to two other fuels. It can be seen from Figure 13 that the last flame contour (up

329 to the $55 \mathrm{~mm}$ diameter) for each fuel reached the optical window periphery in $30,31.5$ and 33 CAD AIT for ethanol, B16I84 and 

and B16I84 blend both reached the piston window at 37.5 CAD AIT, these contours are 1 flame contour (equivalent to 1.5 CAD) before reaching the optical window periphery. Figure 12 shows slightly higher flame radius for the B16I84 slow case in compare 334 to iso-octane slow case at 37.5 CAD AIT. By comparing all the base fuels, it can be seen that the individual cycles selected are in

335 a good agreement with average flame radius growth and in-cylinder pressure data. Set out in Figure 14 are flame contours of 336 Ethanol, B16I84 blend and iso-octane in the case of the highest flame distortion recorded. These cycles were the closest real cycle 337 to 10 averaged cycles at the highest distortion.
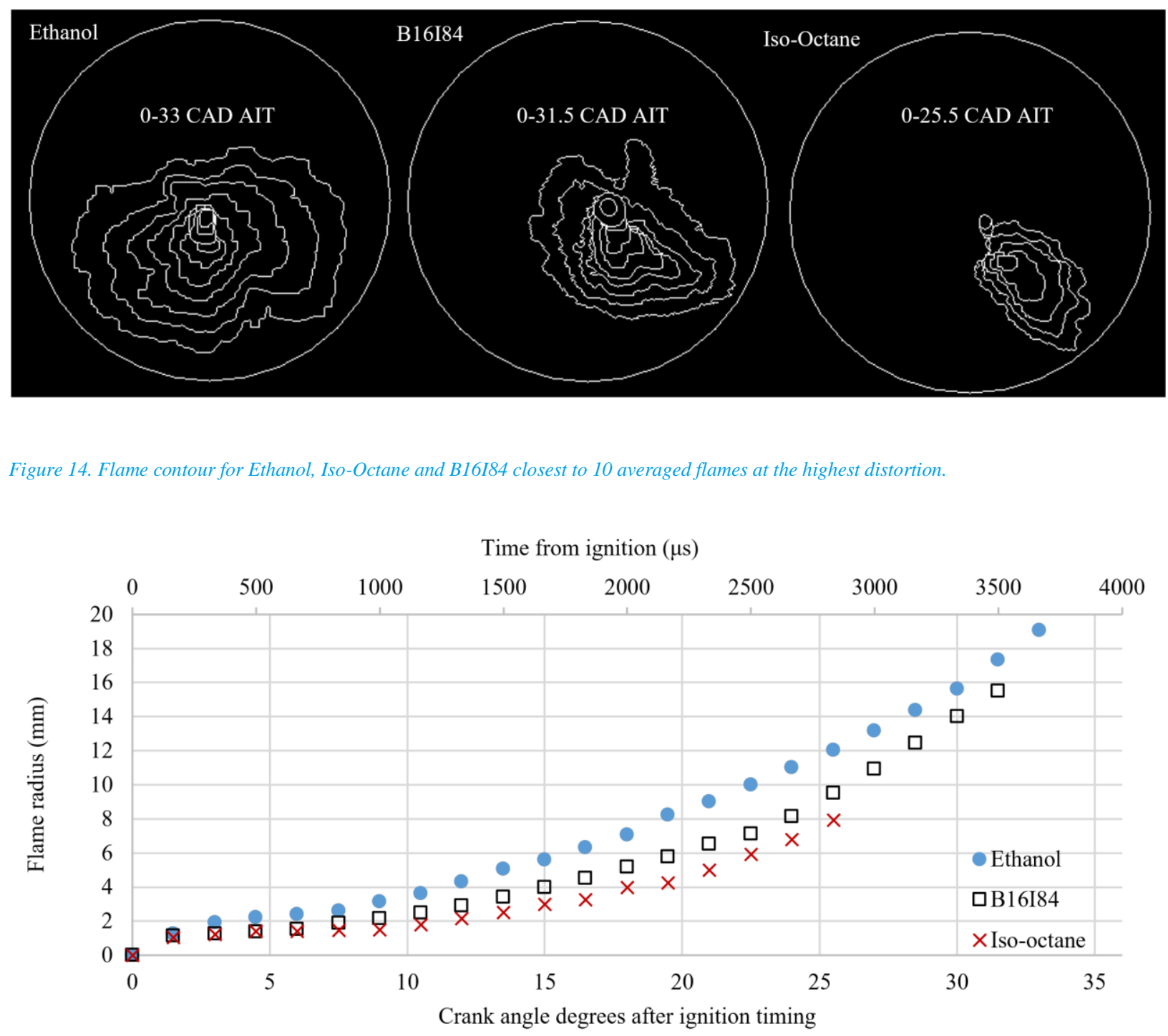


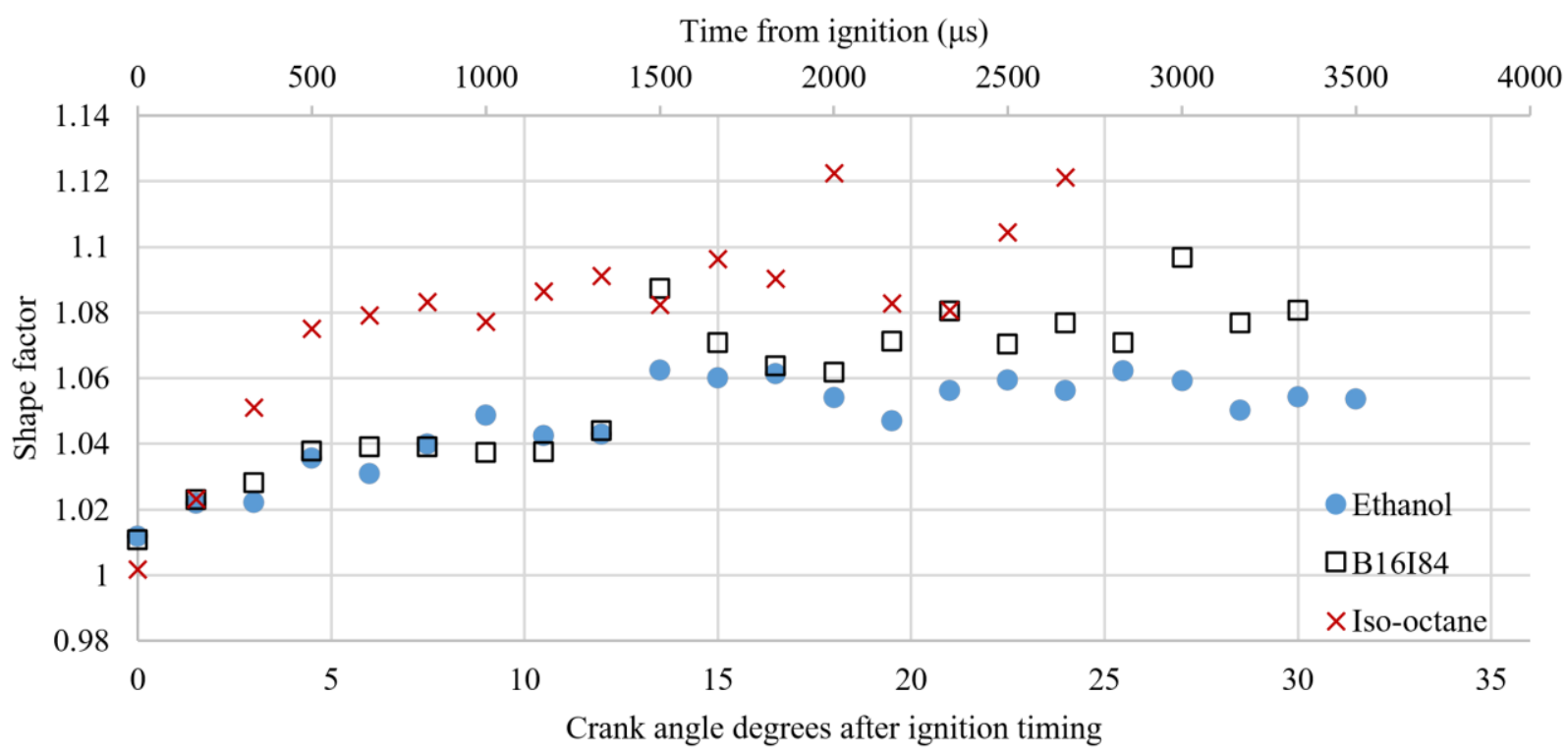

Figure 16. Computed values of shape factor for the three base fuels closest to 10 averaged data at the highest distortion.

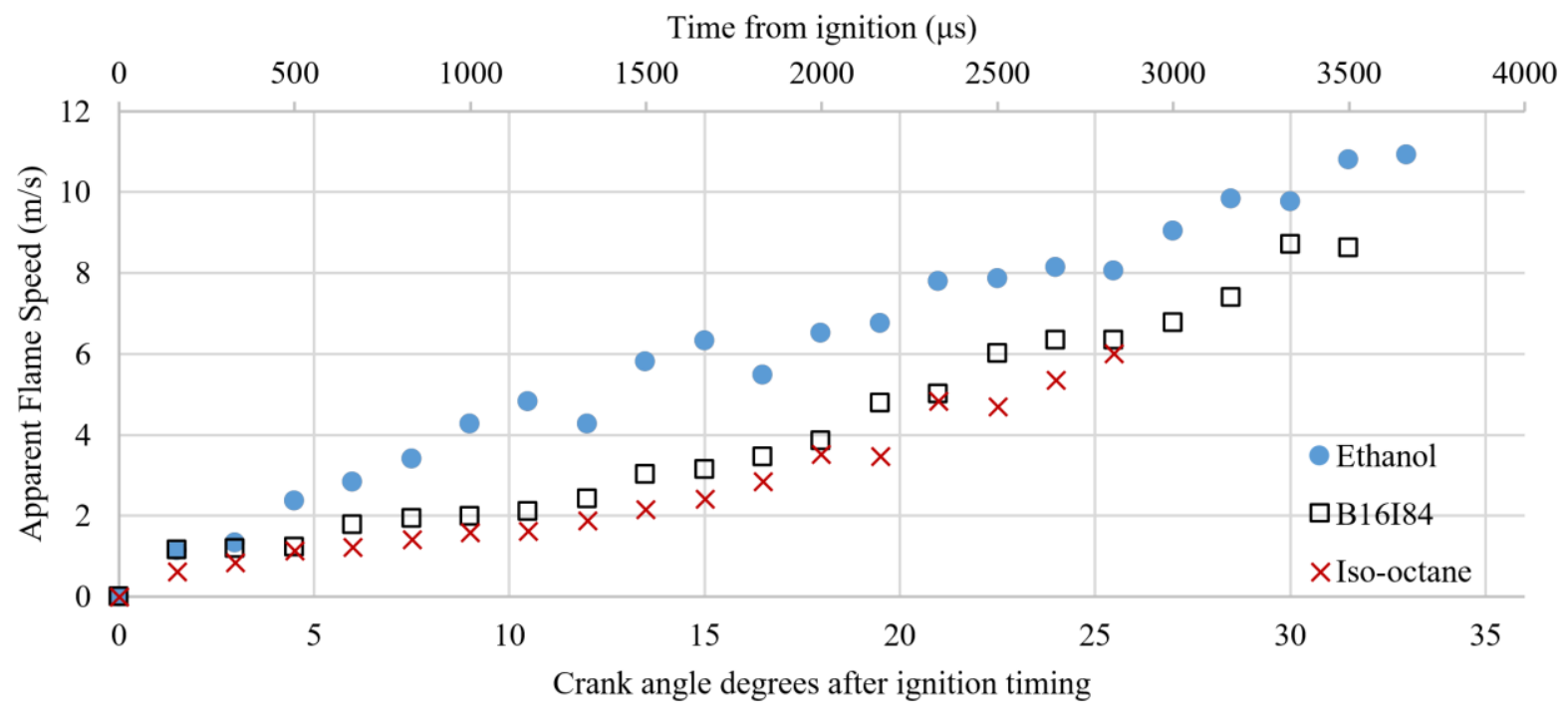

345 Figure 17.Apparent flame speed for the three base fuels closest to 10 averaged data at the highest distortion.

346 Set out in Figure 15 is the computed flame radius growth for the closest cycle to the average. It can be seen that ethanol is the fastest by far compared to all other fuels. Of particular note, the iso-octane and B16I84 cases reached a maximum flame radius of $8 \mathrm{~mm}$ and $14.6 \mathrm{~mm}$ respectively as the flame was stretched toward the bottom right side of the window. This distortion caused the flame centre to move away from the spark plug relatively quickly compared to ethanol, reaching the periphery sooner despite the fact that these were slower burning fuels.

351 Figure 16 shows averaged shape factor profiles for the three base fuels iso-octane exhibited a noticeably higher shape factor, with this slowest burning fuel being exposed to the turbulent spectrum for more time and hence being more distorted. The shape factor 

with higher laminar and hence turbulent burning velocity [33].

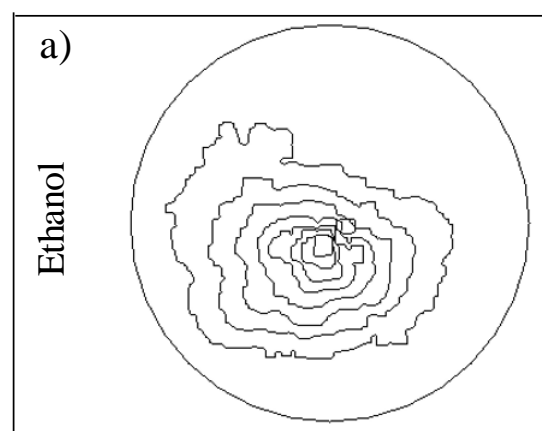

a)

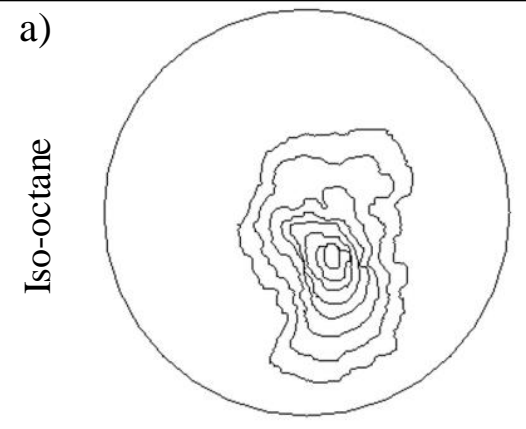

a)

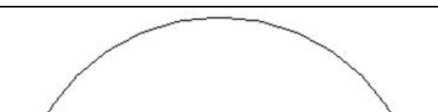

$\frac{\infty}{0}$

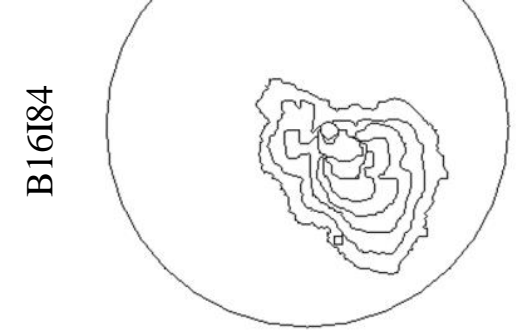

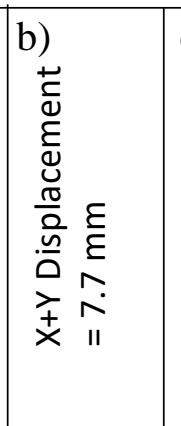

b)

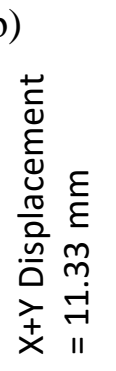

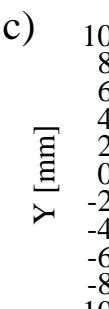

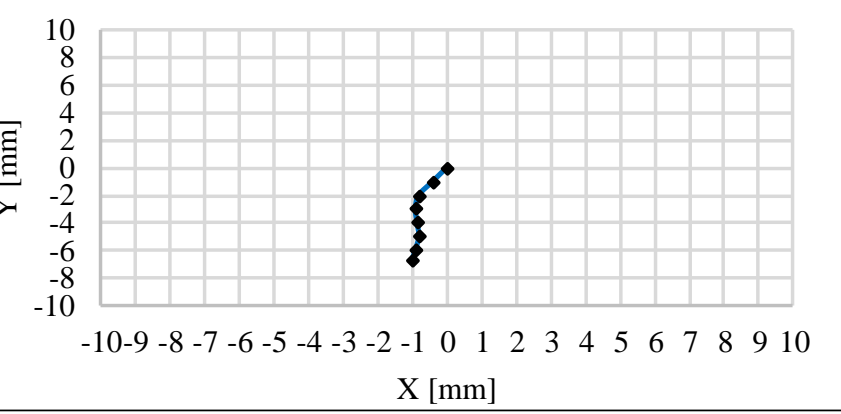

c)

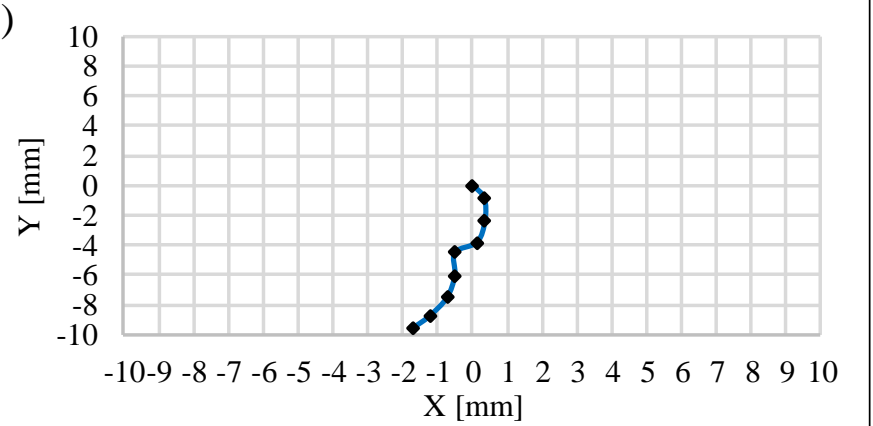

b)

c)

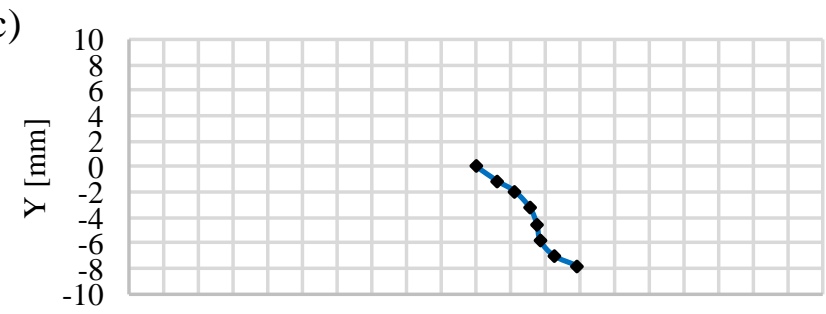

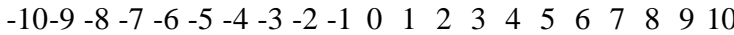
$\mathrm{X}[\mathrm{mm}]$

Figure 18 Flame contour for Ethanol, iso-octane and B16184 closest to 60 averaged flames. b) Euclidean centroid displacement measurement for all 3 fuels closest to 60 averaged flames. $(x=0, y=0)$ indicating spark position. the combustion chamber and that there is no apparent complementary bulk air motion toward any side of the combustion chamber. 
The $(0,0)$ point represents the spark-plug electrode point on the graph. Figure 18 shows the average flame Euclidean distance from the spark plug until one frame (1.5 CAD) before the flame reaches the window periphery. This figure demonstrates the similar trend for all fuels, where the flames grew initially towards the exhaust side of the engine in agreement with previous studies [34]. The ethanol flame contour moved away from its centre by $6.7 \mathrm{~mm}$ in y and $1 \mathrm{~mm}$ in $\mathrm{x}$-direction total of $7.7 \mathrm{~mm}$, compared to isooctane ( $y=9.6 \mathrm{~mm}, \mathrm{x}=1.73 \mathrm{~mm}$ total of 11.33) and B16184 ( $\mathrm{y}=7.8 \mathrm{~mm}, \mathrm{x}=2.9 \mathrm{~mm}$ total of 10.7). The ethanol flame contour moved away from its centre by $6.7 \mathrm{~mm}$ compared to B16I84 $(7.8 \mathrm{~mm})$ and iso-octane $(9.6 \mathrm{~mm})$. This indicates that ethanol is more resistant to flame centroid displacement and flame stretching compared to B16I84 and iso-octane, which is also is in a good agreement with

373 the flame stretch analysis in previous work [44].

374 The flame contours shown in Figure 18 are the closest real cycle contours compared to the average contours for each fuel as computed over 60 cycles. Shown in Figure 19 are corresponding computations of shape factor for the mean cycles. The slower burning iso-octane fuel was subjected to the turbulent spectrum for a prolonged period, which resulted in increased distortion of the mean flame shape as the larger scales of turbulence were encroached towards the end of the visible propagation event. The observation of increased bulk flame distortion leading to slower burning suggests the detrimental effects of flame stretch cancel out any benefits of a larger enflamed area due to higher distortion. This may be associated with the flame tendency to migrate towards the hotter exhaust side of the engine. Recent prior PLIF and emissions measurement work [34] with similar fuels and similar operating conditions indicate the fuel-air charge distribution can be considered to be homogenous in this engine. This observation also compounds the likelihood of the hotter exhaust temperatures leading to the observed flame centroid migration. The flame can only be wrinkled by scales of turbulence smaller than the flame itself; initially, the flame is only wrinkled by the smallest scales of turbulence, larger scales merely convect and distort the flame rather than directly increasing enflamed area. As the kernel develops the larger turbulent scales wrinkle the flame until it reaches a fully developed state. where the entire turbulent spectrum can wrinkle the flame [9]. Shown in Figure 20 is the mean flame radius development for ethanol, B16I84, and iso-octane. The maximum flame radius in this figure is in accordance with the optical piston window restriction of $55 \mathrm{~mm}$ diameter. The flame centroid displacement towards the hotter side of the chamber should also be taken into account. The maximum flame radius reduces to $19.04,15.49$ and $15.42 \mathrm{~mm}$ for ethanol, B16I84 and iso-octane respectively. The flame radius development rate for the iso-octane and B16I84 fuels was very similar within $5 \mathrm{CAD}$ after ignition timing. Ethanol exhibited a notably faster initial flame radius in the period of 0-7 CAD AIT. Overall, ethanol was the fastest propagating fuel followed by B16I84 blend and iso-octane. This seems to be in accordance with burning velocity correlations for ethanol and iso-octane, e.g. [45]. Set out in Figure 21 are values of apparent flame speed for the Iso-octane, Ethanol and B16I84 blend cases derived directly from the flame images closest to the average. The ethanol case exhibits the fastest rate of flame development from the onset, with 


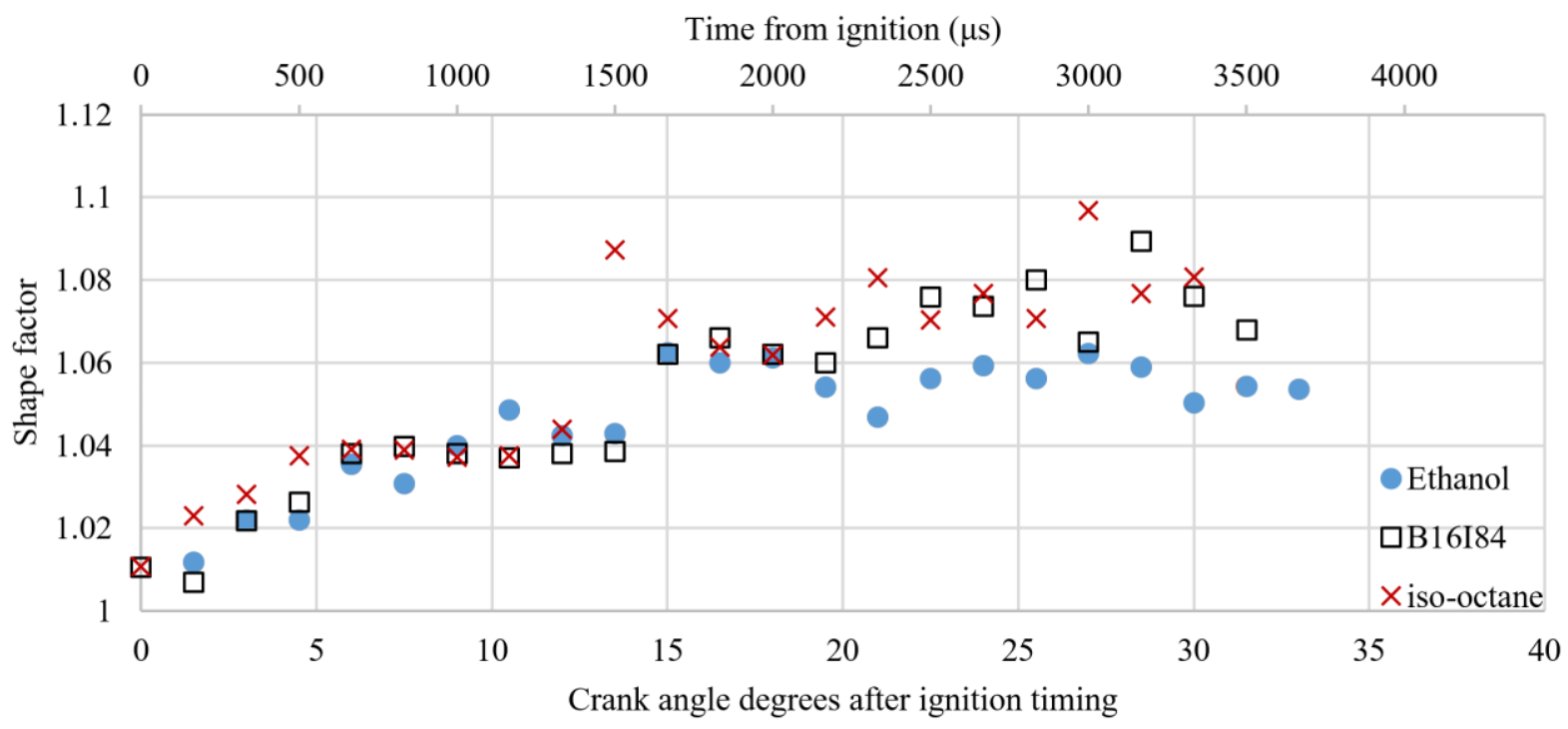

398

Figure 19. Computed shape factor closest data to 60 averaged cycles.

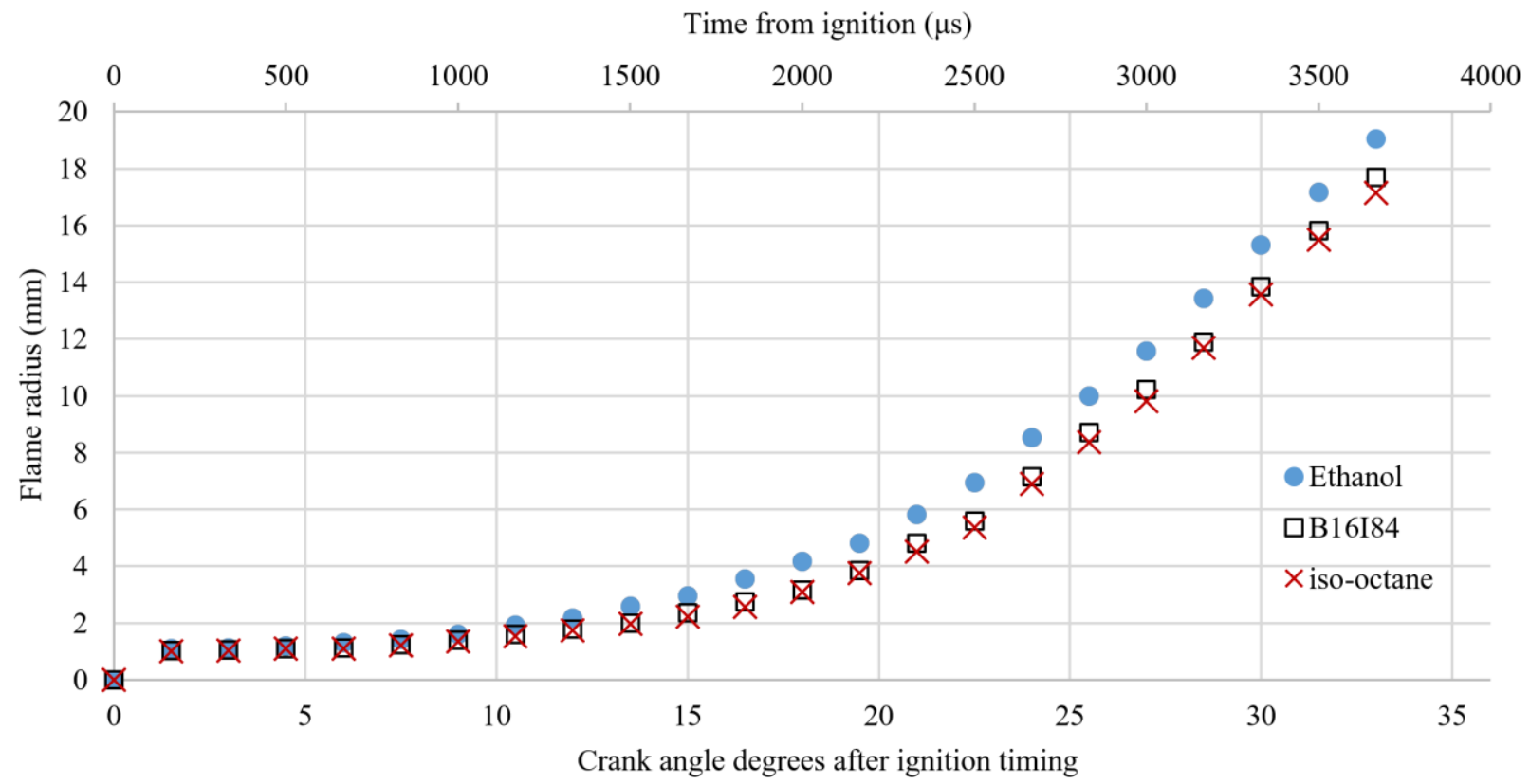

400

401

Figure 20 .Flame radius closest data to 60 averaged cycles. 


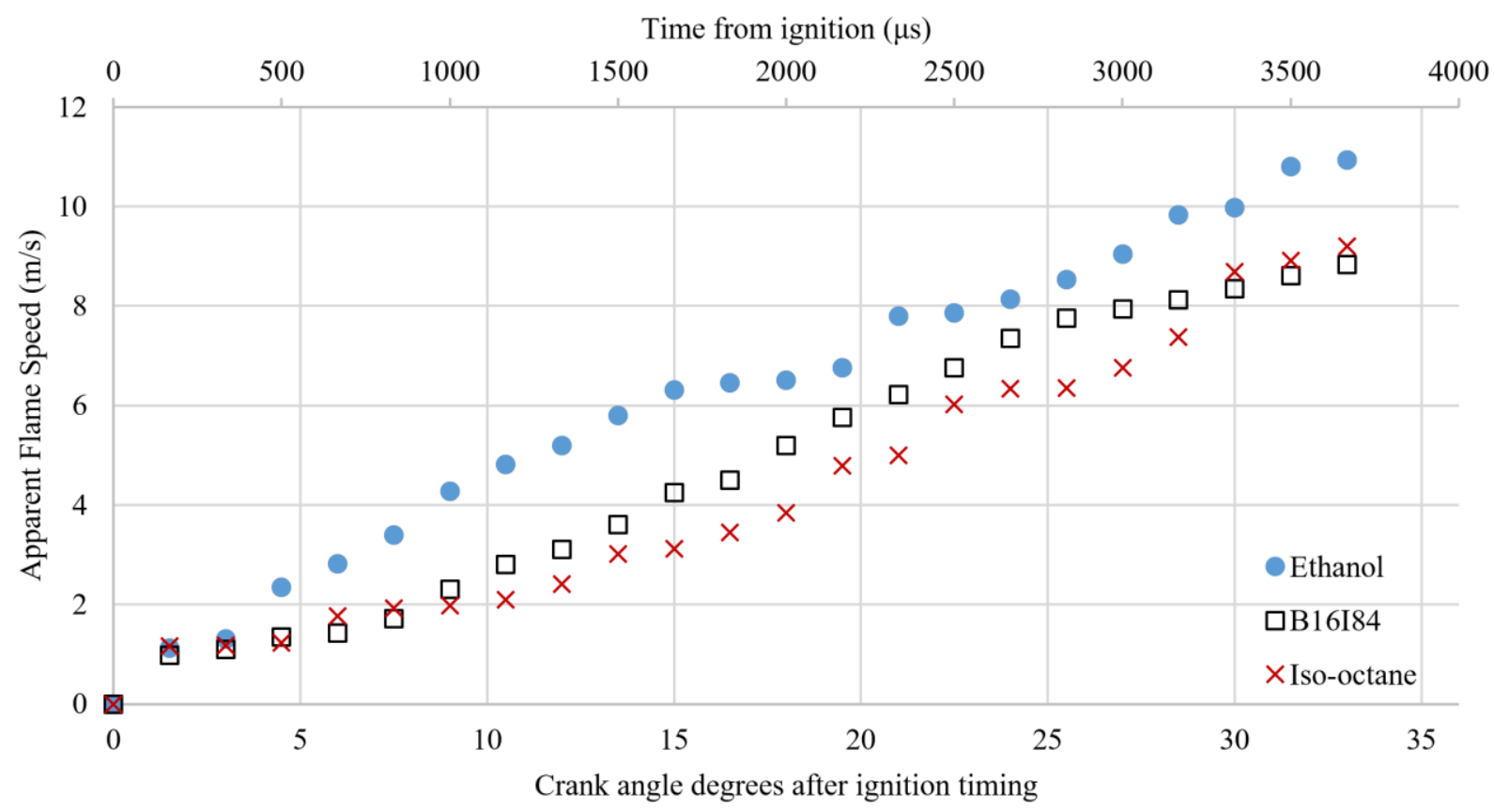

Figure 21.Apparent flame speed closest data to 60 averaged cycles.

\section{Conclusion}

405 Two-dimensional Particle Image Velocimetry (PIV) and flame image analysis has been undertaken and compared to CFD k- $\varepsilon$ RNG

406 modelling to understand the interaction of the in-cylinder flow and flame with alcohol blended fuels in a spark ignition engine with a modern combustion chamber layout. A cycle selection process was developed to provide a robust means to help select "typical" fast, mean and slow burning cycles. Under the limited engine operating conditions tested, the following conclusions were made:

- $\quad$ Particle Image Velocimetry (PIV) experiments indicated that the mean flow-field for this engine on the swirl plane is nearly symmetrical across four divided zones of the combustion chamber.

412 - Comparisons between PIV and CFD data showed very similar velocity magnitudes as the end of compression was approached.

413 At earlier crank angle timings (e.g. $90^{\circ}$ CA BTDC) the CFD results showed a clear difference from the measured values of $414 \quad$ velocity.

415 - Comparing the flame radius development of 60 averaged cycles, ethanol exhibited the faster flame propagation, the rate of 416 mass burning and in-cylinder pressure development in good agreement with burning velocity correlations within the literature.

417 - By adding 16\% n-butanol to Iso-octane the combustion appeared to be faster. An attempt was made to compare these results 418 with burning velocity correlations, which were clearly in a good agreement.

419 - The flame images obtained with all fuels showed a tendency for biased flame growth towards the exhaust valves. The PIV 420 flow field showed no bulk motion toward the exhaust. Prior research has indicated adequate charge homogeneity in this engine 

higher velocities in the horizontal imaging plane. This phenomenon was more likely associated with the hotter wall temperatures at the exhaust side of the bore.

- The currently reported research suggests the flame propagation was moved toward the hotter side of the combustion chamber. Hence the spark plug would ideally be biased further towards the intake side of the chamber if the flame is to approach the intake and exhaust walls at similar times. However, a practical trade-off exists due to the need to maximize the coolant jacket contact around the plug and injector tip while also ensuring the inlet valve size remains maximized for volumetric efficiency.

- Of the fuels tested, the faster propagating ethanol flames showed a reduced tendency for migration towards the exhaust side of the chamber.

Future work may be concerned with the need for side window imaging to eliminate bulk flow effects in the third dimension.

Overall these results may have consequences when designing future combustion chamber layouts when central direct fuel injection is to be adopted.

\section{References}

440 [1] N. Fraser, H. Blaxill, G. Lumsden, and M. Bassett, "Challenges for Increased Efficiency through Gasoline Engine Downsizing,” SAE Int. J. Engines, vol. 2, no. 1, pp. 2009-01-1053, Apr. 2009.

J. W. G. Turner, a. Popplewell, R. Patel, T. R. Johnson, N. J. Darnton, S. Richardson, S. W. Bredda, R. J. Tudor, C. I.

Environ., vol. 18, pp. 62-69, 2013.

M. Bassett, J. Hall, G. Kennedy, T. Cains, J. Powell, and M. Warth, “The Development of a Range Extender Electric Vehicle Demonstrator," in SAE Technical Paper, 2013. 
A. Agarwal, A. Lewis, S. Akehurst, C. Brace, Y. Gandhi, and G. Kirkpatrick, "Development of a Low Cost Production Automotive Engine for Range Extender Application for Electric Vehicles,” in SAE World Congress \& Exhibition, 2016. injection spark ignition engine," Proc. Inst. Mech. Eng. Part D J. Automob. Eng., vol. 227, no. 5, pp. 665-674, May 2013. Relevant to SI Engines,” Sae Tech. Pap. Ser., no. 724, 2000.

[10] A. Cairns and C. G. W. Sheppard, "Cyclically Resolved Simultaneous Flame and Flow Imaging in a SI Engine,” in SAE Technical Paper, 2000, no. 2000-01-2832.

[11] D. Reuss, M. Bardsley, and P. Felton, "Velocity, vorticity, and strain-rate ahead of a flame measured in an engine using particle image velocimetry," SAE Trans., no. 900053, 1990.

[12] D. S. Ting, M. D. Checkel, and B. Johansson, “The Importance of High-Frequency, Small-Eddy Turbulence in Spark Ignited , Premixed Engine Combustion,” SAE Tech. Pap., no. 952409, 1995.

[13] K. Lee, C. Bae, and K. Kang, "The effects of tumble and swirl flows on flame propagation in a four-valve S.I. engine," Appl. Therm. Eng., vol. 27, no. 11-12, pp. 2122-2130, 2007.

[14] V. Salazar and S. Kaiser, "Influence of the Flow Field on Flame Propagation in a Hydrogen-Fueled Internal Combustion Engine," SAE Int. J. Engines, vol. 4, no. 2376-2394, 2011. 
performance and exhaust emissions," Renew. Sustain. Energy Rev., vol. 77, pp. 169-181, 2017.

477 [19] F. G. Kremer, “Alcohol as Automotive Fuel - Brazilian Experience,” SAE Tech. Pap., no. 2000-01-1965, 2000.

$478 \quad$ [20] B. H. West, A. J. López, T. J. Theiss, R. L. Graves, J. M. Storey, and S. A. Lewis, "Fuel Economy and Emissions of the Ethanol-Optimized Saab 9-5 Biopower,” SAE Tech. Pap., no. 2007-01-3994, 2007.

[21] W. M. Griffin, L. B. Lave, and H. L. Maclean, "Promise and Cost of Cellulosic Ethanol for the U . S . Light - Duty Fleet," SAE Tech. Pap., no. 2001-01-2474, 2001.

K. Dohmel, "Future Mobility from a Fuels Perspective," in 29 Internationales Wiener Motorensymposium, 2008.

E. Gnansounou and J. Kenthorai Raman, "Life cycle assessment of algae biodiesel and its co-products,” Appl. Energy, vol. 161, pp. 300-308, 2016.

B. G. Moxey, A. Cairns, and H. Zhao, “A comparison of butanol and ethanol flame development in an optical spark ignition engine," Fuel, vol. 170, pp. 27-38, Apr. 2016. 
octane, gasoline and methane in a direct-injection spark-ignition engine,” Fuel, vol. 109, pp. 256-278, 2013.

503

A. Augoye and P. Aleiferis, "Characterization of Flame Development with Hydrous and Anhydrous Ethanol Fuels in a Spark-Ignition Engine with Direct Injection and Port Injection Systems,” in SAE Technical Paper, 2014.

[33] P. G. Aleiferis and M. K. Behringer, "Flame front analysis of ethanol, butanol, iso-octane and gasoline in a sparkignition engine using laser tomography and integral length scale measurements," Combust. Flame, vol. 162, no. 12, pp. 4533-4552, 2015.

[34] Q. Liu, A. Cairns, H. Zhao, M. Anbari Attar, L. Cruff, and H. Blaxill, "The Effects of Charge Homogeneity and Repeatability on Particulates Using the PLIF Technique in an Optical DISI Engine," SAE Int. J. Engines, vol. 7, no. 1, pp. 500-518, 2014.

[35] J. Beeckmann, O. Röhl, and N. Peters, "Numerical and Experimental Investigation of Laminar Burning Velocities of iso-Octane, Ethanol and n-Butanol,” SAE Int., 2009.

[36] J. Beeckmann, S. Kruse, and N. Peters, "Effect of Ethanol and n-Butanol on Standard Gasoline Regarding Laminar Burning Velocities," Int. Powertrains, Fuels Lubr. Meet., 2010.

[37] C. L. Yaws, "Yaws' Handbook of Thermodynamic and Physical Properties of Chemical Compounds," Knovel. 2003.

[38] P. G. Aleiferis and Z. R. Van Romunde, "An analysis of spray development with iso-octane, n-pentane, gasoline, ethanol and n-butanol from a multi-hole injector under hot fuel conditions," Fuel, 2013.

[39] M. Raffel, C. E. Willert, S. T. Wereley, and J. Kompenhans, Particle Image Velocimetry: A Practical Guide, vol. 2nd. 2007.

[40] M. Raffel, C. E. Willert, and J. Kompenhans, Particle Image Velocimetry. Berlin, Heidelberg: Springer Berlin Heidelberg, 1998.

[41] J. Malcolm, M. Behringer, P. Aleiferis, J. Mitcalf, and D. OudeNijeweme, "Characterisation of Flow Structures in a Direct-Injection Spark-Ignition Engine using PIV, LDV and CFD,” SAE Tech. Pap. 2011-01-1290, no. Ldv, 2011. Mass Transf., vol. 15, no. 2, pp. 301-314, Feb. 1972.

V. Yakhot and S. A. Orszag, "Renormalization group and local order in strong turbulence," Nucl. Phys. B - Proc. Suppl., vol. 2, pp. 417-440, Nov. 1987. 
537 Department of Mechanical Engineering

538 University of Nottingham

539 University Park

540 Nottingham NG7 2RD, United Kingdom

541 Mohsen_mln@hotmail.com

\section{Acknowledgements}

544 The authors would like to thank Dr. Quan Liu, Dr. Jun Ma, Andy Selway and Eamon Wyse for their assistance with the setup of 545 the work.

\section{Definitions/Abbreviations}

$\mathbf{u}^{\prime}$

AFR

ATDC

AV
RMS of the deviations

Air-to-fuel ratio

After top dead centre.

Average velocity. 
B16I84

BDC

BTDC

CA

CA Pmax

CA50

CAD AIT

CFD

COV

DISI

EMOP

fps

I

ICCD

ICE

IMOP

LHV

MBT

PIV
$16 \%$ n-butanol in Iso-octane.

Bottom dead centre

Before top dead centre.

Crank angle

Crank angle location of maximum pressure.

Crank angle location of $50 \%$ mass fraction

burned.

Crank angle degree after ignition timing.

Computational fluid dynamics.

Coefficient of variation.

Direct injection spark ignition.

Exhaust maximum opening point.

Frame per second.

Intensity.

Intensifier charged-couple device.

Internal combustion engine

Intake maximum opening point.

Lower Heating Value

Minimum spark advance for Best

Particle image velocimetry. 


$\begin{array}{ll}\text { Pmax } & \text { Maximum pressure. } \\ \text { RMS } & \text { Root mean square. } \\ \text { RNG } & \text { Re-Normalisation group theory. } \\ \text { RON } & \text { Research octane number. } \\ \text { RPM } & \text { Revolution per minute. } \\ \text { TDC } & \text { Top dead centre. } \\ \text { TI } & \text { Turbulence intensity. } \\ \text { U } & \text { Average velocity. }\end{array}$

